\title{
INDICAÇÕES GEOGRÁFICAS: REGISTROS E PERSPECTIVAS NO ESTADO DE SANTA CATARINA
}

\author{
Stephania Gabriela Lazarotto Zilio ${ }^{1}$ \\ Fernanda Trentin ${ }^{2}$ \\ http://lattes.cnpq.br/7168663965894514
}

RECEBIBO 29/05/2019

APROVADO 30/06/2019

PUBLICADO 01/07/2019

Editor Responsável: Carla Caldas

Método de Avaliação: Double Blind Review

E-ISSN: 2316-8080

DOI:10.16928

No Brasil, há uma disciplina legislativa acerca dos direitos de Propriedade Intelectual, que é gênero, possuindo como espécies a Propriedade Industrial, os direitos autorais e os direitos sui generis. Dentro do gênero "Propriedade Industrial", estudam-se as Indicações Geográficas, que por sua vez, no Brasil, possui duas modalidades, sendo elas, Denominação de Origem e Indicação de Procedência. Tal denominação é utilizada para identificar a origem de produtos ou serviços quando o local tenha se tornado conhecido por sua notória reputação e qualidade. Desta forma, a obtenção desse registro garante aos criadores o direito de usar um selo, ou então uma marca, impedindo que terceiros também possam utilizá-las. O objetivo do presente artigo é analisar os registros já existentes provenientes do Estado de Santa Catarina, avaliando suas perspectivas em relação a outros estados do Sul. Utilizouse a pesquisa bibliográfica, com o método dedutivo. Concluiu, por fim, que Santa Catarina, em comparação com os demais estados da região Sul, está defasado em termos de registros de Indicações Geográficas, bem como de novos registros.

Palavras-chave: Propriedade Intelectual. Propriedade Industrial. Indicação Geográfica. Denominação de Origem. Indicação de Procedência.

\section{GEOGRAPHICAL INDICATIONS: RECORDS AND PERSPECTIVES IN THE STATE OF SANTA CATARINA}

In Brazil, there is a legislative discipline on Intellectual Property rights, Which is In Brazil, there is a legislative discipline on Intellectual Property rights, which is gender, having Industrial Property, copyright and sui generis rights. Within the genus "Industrial Property", we study the Geographical Indications, which in turn, in Brazil, has two modalities, being Denomination of Origin and Indication of Origin. Such denomination is used to identify the origin of products or services when the place has become known for its notorious reputation and quality. In this way, obtaining this registration guarantees creators the right to use a seal, or a trademark, preventing third parties from using them as well. The objective of this article is to analyze the

\footnotetext{
1 Graduanda em Direito, na UNOESC - Campus de São Miguel do Oeste, SC. E-mail: stephaniazilio@outlook.com.

2 Advogada. Professora de Direito Civil e Processo Civil da Universidade do Oeste de Santa Catarina/UNOESC, campus de São Miguel do Oeste/SC. Mestre em Direito pela UFSC Universidade Federal de Santa Catarina. E-mail: fernanda.trentin@unoesc.edu.br.
} 
existing records from the State of Santa Catarina, evaluating its perspectives in relation to other southern states. The bibliographic research was used, using the deductive method. Finally, he concluded that Santa Catarina, in comparison with the other states of the South, is out of date in terms of records of Geographical Indications, as well as new records.

Keywords: Intellectual Property. Industrial Property. Geographical Indication. Denomination of Origin. Indication of Source.

\section{GEOGRAPHICAL INDICACIONES: RECORDS Y PERSPECTIVES EN EL STATE OF SANTA CATARINA}

RESUMEN

En el caso de los países en vías de desarrollo, los Estados miembros de la Unión Europea, En el caso de los genus "Industrial Property", se estudia las indicaciones geográficas, que in turn, in Brazil, tienen dos modalidades, que se denominan "Denominación de Origen e Indication of Origin. La denominación se utiliza para identificar el origen de productos o servicios cuando el lugar ha conocido para su notoriedad y calidad. En este sentido, obtenga este registro creando el derecho a usar el sello, o la marca de marca, la tercera tercera partes de usarlos así. El objetivo de este artículo es analizar los registros existentes del Estado de Santa Catarina, evaluando sus perspectivas en relación con otros estados de la economía. La bibliografía científica se utilizó utilizando el método de deducción. En el caso de Santa Catarina, en comparación con los demás estados del sur, está fuera de fecha en términos de registros de Indicaciones Geográficas, así como nuevos registros.

Palabras clave: Intellectual Property. Industrial Property. Geographical Indication. Denominación de origen. Indicaciones de origen.

\section{INTRODUÇÃO}

O presente artigo tem por finalidade o estudo acerca do instituto denominado Indicação Geográfica, que acolhe junto de si a Indicação de Procedência e a Denominação de Origem. Ainda, integra os ramos da Propriedade Industrial e Propriedade Intelectual. Primeiramente, será abordado o tema que envolve a Propriedade Intelectual. Em seguida, será explanado o instituto da Indicação Geográfica, e por fim, as análises acerca das Indicações Geográficas, com seus registros e perspectivas no Estado de Santa Catarina.

Muitos conhecem ou então já ouviram falar a respeito de várias Indicações Geográficas, como “Queijo Rockford”, “Champagne”, “Vinho Bordeaux”, porém, não imaginam que não se trata de um nome fictício, mas sim, possui ligação com a região onde foi produzido. Portanto, para que se possa compreender o que são as Indicações Geográficas, faz-se necessário conhecer os conceitos de Indicação de 
Procedência e Denominação de Origem, os quais integram a definição de Indicação Geográfica.

A Indicação de Procedência está relacionada ao nome de algum país, cidade, região ou localidade a que tenha sido consolidada uma ótima reputação como centro produtor de determinado produto ao longo dos anos. A Indicação de Procedência não está relacionada a qualquer fator climático, fisiológico ou humano. Neste caso, apenas a fama do local como sendo um centro de grande produção é levada em consideração. Já a Denominação de Origem também está relacionada ao nome de algum país, cidade, região ou localidade, porém, neste caso, possui ligação com as condições geográficas de determinada região, a qual garante qualidades peculiares de determinado produto ou serviço, as quais somente aquele local é capaz de produzir ou oferecer.

Assim, a problemática do presente artigo tem relação com as perspectivas das Indicações Geográficas no Estado de Santa Catarina, analisando-se os principais registros oriundos do Estado, bem como fazendo-se uma análise comparativa com os demais estados do Sul do país.

Para tanto, o artigo fora dividido em três partes, sendo que na primeira, analisará a Propriedade Intelectual e suas espécies. Na segunda, os requisitos para obtenção de uma Indicação Geográfica e, finalmente, analisará os registros catarinenses, fazendo uma análise em relação aos demais estados do Sul, avaliando as perspectivas em relação a Santa Catarina.

\section{A PROPRIEDADE INTELECTUAL}

A Propriedade Intelectual, ou a propriedade das criações intelectuais, da forma como é compreendida atualmente, não deixa vestígios de ter sido usufruída antigamente. Algumas vezes desfrutava-se de algum tipo de proteção contra imitações indevidas, emblemas e brasões. Todos os artistas, mas principalmente os escritores, não possuíam se quer algum tipo de privilégio ou de proteção para suas obras, de modo que estas pudessem livremente serem copiadas ou reproduzidas sem a devida autorização do autor. Com o intuito de evitar o plágio ou a cópia, alguns autores codificavam suas obras em caracteres enigmáticos (DI BLASI, 2010, p. 1). 
Então, constituiu-se a partir do ano de 1967 um órgão autônomo dentro do sistema das Nações Unidas, sendo ele, a Organização Mundial da Propriedade Intelectual (OMPI). Assim, englobou-se a este órgão as Uniões de Berna e de Paris, para que juntas pudessem administrar a Proteção das Obtenções Vegetais, além de diversos outros tratados.

A Convenção da Organização Mundial da Propriedade Intelectual (OMPI), define como Propriedade Intelectual:

(...) a soma dos direitos relativos às obras literárias, artísticas e científicas, às interpretações dos artistas intérpretes e às execuções dos artistas executantes, aos fonogramas e às emissões de radiodifusão, às invenções em todos os domínios da atividade humana, às descobertas científicas, aos desenhos e modelos industriais, às marcas industriais, comerciais e de serviço, bem como às firmas comerciais e denominações comerciais, à proteção contra a concorrência desleal e todos os outros direitos inerentes à atividade intelectual nos domínios industrial, científico, literário e artístico (BARBOSA, 2013, p. 7).

Quando ainda não havia a definição convencional de "Propriedade Intelectual", a mesma enquadrava-se no ramo dos direitos autorais, que são os direitos que todo criador de alguma obra intelectual tem sobre a sua criação, bem como, sobre o seu uso. Tal direito é exclusivo da parte autora e está de acordo com o artigo $5^{\circ}$ da Constituição Federal. Nesta linha, entram os direitos denominados "sui generis", cuja denominação provém do latim, e quer dizer "de seu próprio gênero" ou então "de espécie única", os quais indicam algo que é único e particular de cada pessoa.

Assim, tem-se a noção de Propriedade Intelectual como a de um capítulo do Direito, alcançando o campo da Propriedade Industrial e também dos direitos autorais, bem como, direitos sobre diversos bens imateriais de variados gêneros.BBB

\subsection{PROPRIEDADE INDUSTRIAL}

A Propriedade Industrial é uma matéria muito abrangente que envolve as áreas do Direito, da Ciência, da Técnica e da Economia. De acordo com o entendimento do autor Di Blasi:

(...) a propriedade industrial é um episódio da propriedade intelectual que trata da proteção jurídica dos bens incorpóreos aplicáveis tecnicamente, de forma prática, nos diversos segmentos das indústrias. Aborda assuntos 
referentes às invenções e aos certificados de adição; aos modelos de utilidade; aos desenhos industriais; aos segredos de negócios; aos nomes de domínios; às marcas de produto ou de serviço, de certificação, coletivas e tridimensionais; à repressão a falsas indicações geográficas e demais indicações; e à repressão à concorrência desleal (DI BLASI, 2005, p. 30).

Ainda, conforme a análise do autor Di Blasi, "as invenções, os certificados de adição, os modelos de utilidade e os desenhos industriais são criações suscetíveis de serem convertidas tecnicamente em bens corpóreos industrializáveis" (DI BLASI, 2010, p. 25).

O ramo da Propriedade Industrial não reconhece apenas o valor dos aspectos técnicos funcionais de determinado objeto, mas sim, o valor de uma aparência deste mesmo objeto, desde que seja funcional. Assim, é conferido à esta aparência uma proteção que poderá ser obtida a partir do sistema de patentes, como é o caso dos Estados Unidos, ou ainda, através de registro de desempenho industrial, assim realizados no Brasil e no Canadá (DI BLASI, 2005, p. 381).

A repressão à concorrência desleal, tratada no âmbito da Propriedade Industrial, tem como objetivo principal reprimir ou impedir atos de concorrência que contrariam os usos éticos e honrados no campo da indústria e do comércio.

Conforme preceitua o autor Di Blasi:

(...) considera-se a concorrência desleal quando se utiliza de artifícios repreensíveis, capazes de captar a clientela de empresas com intenções de auferir vantagens a estas pertencentes. A repressão a concorrência desleal não trata, no entanto, da concessão de direitos de proteção. Objetiva a disciplina dos meios e recursos contra os atos de competidores que infrinjam os usos honrados. Atua contra os atos que induzam a confundir o público quanto a produtos e atividades industriais, comerciais ou de serviços, de um competidor. Por outro lado, age contra falsas alegações que tendam a promover o descrédito da empresa, do produto ou da sua atividade e que induzam o público consumidor a erros quanto às características do produto e aos meios de produção (DI BLASI, 2010, p. 26).

O campo da Propriedade Industrial engloba o sistema de Marcas, Patentes, Desenhos Industriais, entre outros institutos regulamentados pela Lei 9.279/96, a qual regula os direitos e obrigações relativos à Propriedade Industrial, os quais compreenderemos melhor abaixo.

As marcas são sinais que nos permitem distinguir os produtos industriais, artigos comerciais e serviços profissionais de outros do mesmo gênero, da mesma atividade, semelhantes ou afins, de origens diversas. Para nós, consumidores, a 
marca nos representa uma orientação na hora de comprar alguma coisa, levando em conta diversos fatores, como por exemplo, qualidade e desempenho de tal bem. Neste sentido, é englobado o desenho industrial, ou então, design, que pode ser entendido como a forma ou aparência de algum produto, bem como seus desenhos, suas linhas, seus arranjos, suas características, formas, contornos, texturas, etc.

Partindo para a área das patentes, podemos compreendê-las como:

(...) o conjunto das regras que tratam da proteção das invenções voltadas para todos os segmentos da indústria. A patente é o direito outorgado pelo Governo de uma nação a uma pessoa, o qual confere exclusividade de exploração do objeto de uma invenção ou de um modelo de utilidade, durante um determinado período, em todo o território nacional (DI BLASI, 2005, p. 53).

As patentes se subdividem em dois grupos, sendo eles a patente de invenção e a patente de modelo de utilidade. A patente de invenção nada mais é do que a criação de algo que antes não existia, ou seja, é algo novo e original, que também pode ser feito por meio de uma descoberta de algo já existente, mas que por suas características e qualidades específicas foi possível criar algo totalmente inovador. Já a patente de modelo de utilidade é uma nova forma ou disposição que irá resultar em melhoria funcional ao uso de algum objeto e até mesmo na sua fabricação, que poderá estar predisposta à aplicação industrial. Aqui, não há que se falar em invenção, mas sim, em acréscimo positivo na utilidade de algo que já está lançado no mercado. Desta forma, a melhoria de tal utilidade possui proteção autônoma.

O sistema de desenhos industriais, conhecido também por "design" que provém da origem inglesa, abrange diversos conceitos referentes à configuração e formação de um projeto que possa ser produzido industrialmente. Os conceitos fazem referência à forma plástica, bem como às linhas, cores, formas, contornos, ornamentações e texturas de uma mesma peça.

De acordo com o entendimento do autor Di Blasi:

(...) o desenho industrial é um tipo de criação intelectual que envolve tanto características funcionais quanto estéticas de um mesmo objeto. De acordo com a Organização Mundial da Propriedade Intelectual - OMPI, os desenhos industriais são o ponto de encontro entre arte e tecnologia, uma vez que os desenhistas se empenham em criar produtos cujas formas e aparência satisfaçam as preferências estéticas dos consumidores, bem como suas expectativas com relação à performance funcional do produto (DI BLASI, 2010, p. 335). 
Ainda, temos as Indicações Geográficas, a qual a Lei n. 9.279 não as conceitua diretamente, mas o faz por meio de duas espécies: a Indicação de Procedência (IP) e a Denominação e Origem (DO). Define a Lei nº 9.279/1996 (Lei da Propriedade Industrial), em seu artigo 177, que Indicação de Procedência é "o nome geográfico de país, cidade, região ou localidade de seu território, que se tenha tornado conhecido como centro de extração, produção ou fabricação de determinado produto ou de prestação de determinado serviço", ao passo que o artigo 178 da referida lei delimita o conceito de Denominação de Origem como "o nome geográfico de país, cidade, região ou localidade de seu território, que designe produto ou serviço cujas qualidades ou características se devam exclusiva ou essencialmente ao meio geográfico, incluídos fatores naturais e humanos". Os dois conceitos são necessários para configuração da Indicação Geográfica, conforme será explicado em tópico subsequente.

\subsubsection{LEGISLAÇÃO ACERCA DO TEMA}

A Lei nº 9.279 de 14 de maio de 1996, intitulada como Código Brasileiro da Propriedade Industrial, dispõe sobre os direitos e obrigações relativos à Propriedade Industrial submetidas a legislação brasileira:

Art. $1^{\circ}$ Esta Lei regula direitos e obrigações relativos à propriedade industrial.

Art. $2^{\circ} \mathrm{A}$ proteção dos direitos relativos à propriedade industrial, considerado o seu interesse social e o desenvolvimento tecnológico e econômico do País, efetua-se mediante:

I - Concessão de patentes de invenção e de modelo de utilidade;

II - Concessão de registro de desenho industrial;

III - Concessão de registro de marca;

IV - Repressão às falsas indicações geográficas; $e$

$\mathrm{V}$ - Repressão à concorrência desleal.

Ainda, os autores de inventos industriais têm proteção prevista constitucionalmente como direito fundamental, disposto no artigo $5^{\circ}$ da Constituição Federal, em seus incisos XXVI, XXVIII e XXIX:

Art. $5^{\circ}$ Todos são iguais perante a lei, sem distinção de qualquer natureza, garantindo-se aos brasileiros e aos estrangeiros residentes no País a 
inviolabilidade do direito à vida, à liberdade, à igualdade, à segurança e à propriedade, nos termos seguintes:

XXVI - aos autores pertence o direito exclusivo de utilização, publicação ou reprodução de suas obras, transmissível aos herdeiros pelo tempo que a lei fixar;

XXVIII - são assegurados, nos termos da lei:

a) A proteção as participações individuais em obras coletivas e a reprodução da imagem e voz humanas, inclusive nas atividades desportivas;

b) O direito de fiscalização do aproveitamento econômico das obras que criarem ou de que participarem aos criadores, aos intérpretes e as respectivas representações sindicais e associativas;

XXIX - a lei assegurará aos autores de inventos industriais privilégio temporário para sua utilização, bem como proteção às criações industriais, à propriedade das marcas, aos nomes de empresas e a outros signos distintivos, tendo em vista o interesse social e o desenvolvimento tecnológico e econômico do País;

Além das normas constitucionais e infraconstitucionais, o INPI edita normas administrativas que regulam o procedimento de análise e concessão, tema que será abordado em capítulo próprio.

\section{INDICAÇÃO GEOGRÁFICA}

A Indicação Geográfica é conhecida há muito tempo nos países que possuem a tradição de produzir vinhos e produtos alimentícios, como por exemplo, Itália, França e Portugal.

No Brasil, o termo "Indicação Geográfica" foi inserido pelo advento da promulgação da Lei da Propriedade Industrial, n. 9.279 de 14 de maio de 1996, denominada de LPI/96.

No presente tópico, serão abordados o conceito e a legislação acerca do tema, para posteriormente introduzir ao objeto da pesquisa, qual seja, as perspectivas das indicações geográficas no estado de Santa Catarina.

\subsection{ACORDO TRIPS}

O Acordo sobre Aspectos dos Direitos de Propriedade Intelectual relacionados ao Comércio, denominado de Acordo TRIPS, estipula padrões mínimos 
de proteção a serem observados, envolvendo relações de direitos autorais, marcas, indicações geográficas, desenhos industriais, patentes, circuitos integrados e informação confidencial (ITAMARATY, 2018).

O Acordo traz uma conceituação mais ampla, sem distinguir as espécies de indicações geográficas, porém, regulamentou o termo Indicação Geográfica, conceituando-o como sendo:

Art. 22: (...) Indicações que identifiquem um produto como originário do território de um Membro, ou região ou localidade deste território, quando determinada qualidade, reputação ou outra característica do produto seja essencialmente atribuída à sua origem geográfica (OMC, 1994).

A Lei da Propriedade Industrial teve como um de seus objetivos, incorporar a seu texto os parâmetros mínimos que se encontram alocados no Acordo TRIPS, porém, a referida Lei não é totalmente compatível com o Acordo.

\subsection{INDICAÇÃO DE PROCEDÊNCIA E DENOMINAÇÃO DE ORIGEM}

A Indicação de Procedência é conceituada na Lei nº 9279/96 (Lei de Propriedade Industrial) "como o nome geográfico de país, cidade, região ou localidade de seu território, que se tenha tornado conhecido como centro de extração, produção ou fabricação de determinado produto ou de prestação de determinado serviço"

Quanto à Denominação de Origem, a Lei de Propriedade Industrial em seu artigo 178, define como: "o nome geográfico de país, cidade, região ou localidade de seu território, que designe produto ou serviço cujas qualidades ou características se devam exclusiva ou essencialmente ao meio geográfico, incluídos fatores naturais e humanos".

A grande característica que evidencia a Indicação Geográfica é a notoriedade do meio geográfico de origem que está relacionada ao produto ou serviço que ali fora originado. Porém, não devemos confundir: a tradição do local não é um elemento que integra a Indicação de Procedência, pois ela é mais restritiva que a notoriedade do produto ou serviço, uma vez que, exige-se práticas reiteradas no tempo que são associadas à cultura de uma região ou população. Ainda, pode ser 
definida como a "transmissão ou entrega de valores de uma geração a outra" (IBGE, 2008, p. 7).

Assim, é possível compreender que a tradição deve ou então deveria ser um elemento que fosse capaz de integrar a conceituação legal das Indicações de Procedência. A diferença consiste apenas "no fato de que se amparando somente no requisito da notoriedade é possível "criar" uma IP, por exemplo, por meio de investimentos em marketing a curto prazo, dando-lhe a devida notoriedade". Por outro lado, compreende-se que uma Indicação Geográfica deve ser reconhecida e não construída, especialmente se estiver se tratando de uma notoriedade passageira (LOCATELLI, 2016, p. 4).

Apesar de não existir exigência legal no Brasil, os pedidos de Indicação de Procedência, em regra, possuem relação com produtos que envolvem tradição e possuem vínculo com a cultura de determinado local, o que se torna importante para o reconhecimento e valorização dos produtos e serviços perante o mercado consumidor, da mesma forma para com os produtores ou prestadores de serviços (LOCATELLI, 2016. p. 4).

O nome geográfico não precisa, necessariamente, se referir a um município ou distrito previamente reconhecido, sendo possível realizar a demarcação da área de acordo com suas peculiaridades, dinamicidade e abrangência de cada indicação. Para isso, é necessário somente um documento oficial que reconheça o nome geográfico pertinente à área geográfica a ser demarcada (LOCATELLI, 2016. p. 4).

No conceito legal de Indicação de Procedência, não existe qualquer exigência relacionada à qualidade ou característica do produto que esteja vinculado ao meio geográfico de origem, apenas basta que este meio seja reconhecido. Aqui, encontramos a principal diferença entre Indicação de Procedência de Denominação de Origem, uma vez que, a Lei a conceitua como "o nome geográfico de país, cidade, região ou localidade de seu território, que designe produto ou serviço cujas qualidades ou características se devam exclusiva ou essencialmente ao meio geográfico, incluídos fatores naturais e humanos" (BRASIL, 1996 - art. 178).

Portanto, a Denominação de Origem necessita de um vínculo mais objetivo com o meio geográfico de origem, que é a comprovação de uma característica ou qualidade que esteja vinculada a esse. Se trata de produtos diferenciados ou únicos, que acabam se diferenciando dos demais justamente pela origem geográfica, devendo possuir um vínculo comprovado com este meio, incluídos fatores naturais e PIDCC, Aracaju/Se, Ano VIII, Volume 13 no 02, p.086 a 114 Jul/2019 | www.pidcc.com.br 
INDICAÇÕES GEOGRÁFICAS: REGISTROS E PERSPECTIVAS NO ESTADO DE SANTA CATARINA E-ISSN 2316-8080

humanos. Assim, a legislação trata dos fatores naturais "e" humanos, fazendo com que seja possível interpretar que ambos devam estar presentes, como por exemplo, questões relacionadas ao clima, solo e altitude. Uma questão que acaba sendo controversa é a necessidade ou não da notoriedade como requisito para a Denominação de Origem. Com base nos requisitos legais, a notoriedade é dispensável (LOCATELLI, 2016. p. 5).

Existe uma tendência que nos leva a confundir Indicação Geográfica com o produto que ela designa. Porém, neste caso, o que se protege e registra é o nome geográfico e sua representação gráfica, caso exista, fazendo com que sejam delimitados os produtos ou serviços a ele relacionados no Regulamento de Uso. Como exemplo, pode-se citar que foi registrado "Cerrado Mineiro" para café, portanto, será esse 'nome' protegido, o qual irá no selo ou rótulo do produto com Indicação Geográfica, e não "Café do Cerrado Mineiro". Por outro lado, tais nomes geográficos podem acabar caindo em uso comum, passando a serem associados pelo consumidor à uma espécie ou gênero de produtos e não mais o local de origem deles. Exemplos muito comuns a serem citados são as Indicações Geográficas europeias que possuem grande notoriedade no Brasil e que facilmente são confundidas com gênero ou espécie de algum produto, como por exemplo, a Champagne. Nessa perspectiva, a legislação brasileira estabeleceu exceções à proteção de um nome geográfico como Indicação Geográfica quando houver se tornado genérico (LOCATELLI, 2016. p. 5).

A Lei da Propriedade Industrial proíbe, ainda, que o nome geográfico que constitua uma Indicação Geográfica sirva de elemento constitutivo para a marca. Partindo do ponto de que o registro de Indicação Geográfica é declaratório, esse não deve ser requisito para gozar de proteção. No Brasil, há uma forte tradição no registro de marcas em relação à Indicação Geográfica, fazendo com que alguns nomes geográficos que hoje constituem uma Indicação Geográfica já tenham sido reconhecidos como marca. Portanto, a posição do INPI (Instituto Nacional da Propriedade Industrial) para este caso, tem sido a coexistência, não negando o registro posterior do signo geográfico, até mesmo por se tratar de um registro declaratório (LOCATELLI, 2016. p. 6).

Por fim, no tocante a titularidade, esta é restrita aos produtores ou prestadores de serviços que estejam estabelecidos na área geográfica demarcada. 
Além disso, considerando a definição legal e o objetivo, para a Denominação de Origem é exigido que sejam cumpridos os requisitos de qualidade que a caracterizam, conforme estabelece o artigo 182 da Lei de Propriedade Industrial.

\subsection{DEFINIÇÃO DE INDICAÇÃO GEOGRÁFICA}

A Indicação Geográfica (IG) é utilizada para identificar a origem de produtos ou serviços quando determinado local tenha se tornado conhecido por determinada característica ou qualidade do produto ou serviço, que se tornou peculiar daquela região e a legislação que regula os direitos e obrigações acerca das Indicações Geográficas é a Lei n. 9.279 de 1996, chamada de Lei da Propriedade Industrial.

A Lei n. 9.279 não conceitua expressamente a Indicação Geográfica, mas acaba conceituando-a por meio de duas espécies, sendo elas: a Indicação de Procedência (IP) e a Denominação e Origem (DO).

A Lei da Propriedade Industrial obteve os parâmetros mínimos necessários reconhecidos pela comunidade internacional para sua concretização, permitindo que o processo de reconhecimento fluísse da melhor forma possível, ainda que com regras mínimas.

\section{REGULAMENTAÇÃO DAS INDICAÇÕES GEOGRÁFICAS PELO INPI}

O Instituto Nacional da Propriedade Industrial é uma autarquia federal vinculada ao Ministério do Desenvolvimento, Indústria e Comércio Exterior (MDIC) e responsável pelo reconhecimento das Indicações Geográficas no Brasil. Compete a Autarquia a análise dos requerimentos de Indicações Geográficas, conforme estabelece a Lei $n^{\circ}$ 9.279/96 (Lei de Propriedade Industrial), in verbis:

\footnotetext{
Art. 182. O uso da indicação geográfica é restrito aos produtores e prestadores de serviço estabelecidos no local, exigindo-se, ainda, em relação às denominações de origem, o atendimento de requisitos de qualidade.

Parágrafo único. O INPI estabelecerá as condições de registro das indicações geográficas.
}

Assim, o Instituto Nacional da Propriedade Industrial atua diretamente na proteção das Indicações Geográficas, com o intuito de evitar a utilização indevida de 
determinado produto ou serviço. Para que isso seja possível, é necessário obter o registro junto ao $\mathrm{INPI}$, o qual configura um fator decisivo para que a proteção do nome geográfico seja garantida e protegida. Assim, o produto ou serviço se tornará diferenciado dos demais disponíveis no mercado.

O registro de Indicação Geográfica serve para delimitar a área onde o produto é produzido ou onde serviço é oferecido, sendo o uso da IG restringido aos produtores e prestadores de serviços de tais regiões. Ainda, com a obtenção do registro, tem-se o impedimento da utilização do nome da região em produtos ou serviços de forma indevida, lembrando que a legislação vigente não tem prazo de validade previsto para o registro de uma Indicação Geográfica, o que acaba se tornando um grande atrativo para as pessoas que possuem interesse nessa prática.

\subsection{PROCEDIMENTO DE REGISTRO DAS INDICAÇÕES GEOGRÁFICAS}

Os produtores ou prestadores de serviços devem estar organizados numa entidade representativa de determinada localidade para que possam solicitar o procedimento perante o INPI. Para tanto, será avaliado a estrutura hierárquica e logística da entidade e os requisitos comprobatórios para configuração da Indicação de Procedência ou da Denominação de Origem.

Cumprido os requisitos mínimos, os produtores, prestadores de serviço ou a entidade representativa solicitará perante o INPI o registro de Indicação Geográfica, que é regulado pela Instrução Normativa 25/2013, que requer para análise do pedido o comprovante de pagamento do Guia de Recolhimento da União, o preenchimento de formulário com o requerimento da Indicação Geográfica, aposto o nome geográfico pretendido, a delimitação da área e do produto abarcado pela proteção requerida no formulário.

Atendidos todos os requisitos determinados pelo Instituto Nacional da Propriedade Industrial, será concedida a Indicação Geográfica solicitada.

\subsection{DIREITO COLETIVO DE USO DA INDICAÇÃO GEOGRÁFICA}

A concessão do uso de Indicação Geográfica pelo INPI em determinada localidade permite o uso da distinção pelos empreendedores da região. Nesse 
sentido, trata-se de direito coletivo, considerando que se referem a direitos de pessoas ligadas entre si por uma classe de pessoas (abrangidas pelas Indicações Geográficas) que, embora utilizem coletivamente a indicação, são passíveis de identificação individual.

Nesse sentido, Peña de Moraes conceitua direito coletivo "como direitos fundamentais próprios do homem-membro de uma categoria, classe ou grupo, porque titularizados e exercidos por pessoas coletivamente consideradas entre si, com determinabilidade de seus membros, ou não" (MORAES, 2017).

Em análise do tema, Paesani reitera o caráter coletivo da Indicação Geográfica, como se observa no recorte doutrinário:

Cabe assinalar o caráter coletivo dos direitos sobre uma indicação
geográfica. Trata-se de um direito de uso exclusivo: somente o titular pode
exercê-lo e qualquer interessado, estabelecido na região ou localidade
geográfica, está potencialmente legitimado a usar a indicação geográfica
para assinalar o seu produto. É este o entendimento do art. 182: "uso da
indicação geográfica é restrito aos produtores e prestadores de serviços
estabelecidos no local". Quando a indicação se torna de uso comum, deixa
de ser considerada indicação geográfica. O INPI estabelecerá as condições
de registro das indicações geográficas. (PAESANI, 2015)

Considerando a característica de coletividade, e em se tratando de tema vinculado à ordem econômica, entende-se pela possibilidade da atuação do Ministério Público e de associação regularmente constituída para defesa dos interesses relacionados a Indicação Geográfica, tendo em vista as disposições da Lei de Ação Civil Pública (Lei Federal n 7.347/85):

Art. $1^{\circ}$ Regem-se pelas disposições desta Lei, sem prejuízo da ação popular, as ações de responsabilidade por danos morais e patrimoniais causados:

(...)

IV - a qualquer outro interesse difuso ou coletivo.

$\checkmark$ - por infração da ordem econômica

$(\ldots)$

Art. $5^{\circ}$ Têm legitimidade para propor a ação principal e a ação cautelar:

I - o Ministério Público;

$(\ldots)$

V - a associação que, concomitantemente:

a) esteja constituída há pelo menos 1 (um) ano nos termos da lei civil;

b) inclua, entre suas finalidades institucionais, a proteção ao patrimônio público e social, ao meio ambiente, ao consumidor, à ordem econômica, à livre concorrência, aos direitos de grupos raciais, étnicos ou religiosos ou ao patrimônio artístico, estético, histórico, turístico e paisagístico. 
INDICAÇÕES GEOGRÁFICAS: REGISTROS E PERSPECTIVAS NO ESTADO DE SANTA CATARINA

E-ISSN 2316-8080

Diferente da Denominação de Origem, a Indicação Geográfica permite um desenvolvimento regional e a estimulação do pequeno e médio produtor, por se tratar de direito coletivo.

No entanto, a instituição do direito de Indicação Geográfica não permite a violação dos princípios contratuais da boa-fé e da concorrência leal. Qualquer atuação que configure em dissimulação do uso perante os consumidores é considerada ilícita, como se observa nas jurisprudências do Superior Tribunal de Justiça.

No julgamento do Agravo em Recurso Especial $\mathrm{n}^{\circ}$ 1.185.538, o Superior Tribunal de Justiça analisando as definições da Lei de Propriedade Industrial, concluiu que o uso do vocábulo "Curitiba" não possui a proteção legal conferida a uma Indicação de Procedência ou Denominação de Origem, considerando que o vocábulo questionado não se trata de elaboração de produtos ou prestação de serviços, nos termos do art. 182 da LPI:

RECURSO ESPECIAL - AÇÃO DE OBRIGAÇÃO DE FAZER C/C REPARAÇÃO DE DANOS - USO DE VOCÁBULO "CURITIBA", INTEGRANTE DE MARCA MISTA DEVIDAMENTE REGISTRADA NO INSTITUTO NACIONAL DE PROPRIEDADE INDUSTRIAL (INPI), POR EMPRESA CONCORRENTE, QUE O AGREGOU AO SEU NOME COMERCIAL - TRIBUNAL A QUO QUE REPUTA VIOLADO O ART. 129 DA LEI DE PROPRIEDADE INTELECTUAL (LEI N 9.279/1996) E DETERMINA SEJAM ADOTADAS PROVIDÊNCIAS PARA FAZER CESSAR TODA E QUALQUER REFERÊNCIA AO VOCÁBULO "CURITIBA" ANTE O FATO DE A REPRODUÇÃO PARCIAL DA MARCA PRÉ-REGISTRADA CAUSAR DÚVIDA AOS CONSUMIDORES - PLEITO INDENIZATÓRIO NÃO ACOLHIDO EM RAZÃO DA AUSÊNCIA DE PROVA QUANTO AO PREJUÍZO - INSURGÊNCIA DA PARTE RÉ - RECURSO ESPECIAL PROVIDO. Hipótese: A controvérsia relaciona-se à possibilidade de uso de vocábulo constante de marca mista registrada e a eventual configuração de concorrência desleal. 1. O elemento característico ou diferenciador de nome de empresa ou de título de estabelecimento será óbice ao registro da marca (art. 124, inciso V, da Lei $n^{\circ}$ 9.279/1996 - LPI), quando a proteção ao nome empresarial for conferida em âmbito nacional. 2. A vedação à registrabilidade de vocábulos ou sinais de caráter genérico ou de uso comum deve ser analisada à luz de sua aplicabilidade ao produto ou serviço que se pretende identificar, e não com vistas à própria palavra ou sinal examinados isoladamente. Na hipótese, o termo "Curitiba" não se relaciona diretamente com o serviço cuja individualização se busca com o registro da marca - venda de veículos - tampouco com as características inerentes ao serviço identificado, motivo pelo qual não incide a vedação prevista no art. 124, inciso VI, da Lei nº 9.279/1996. 3. O vocábulo "Curitiba" não ostenta as características próprias de indicação de procedência ou denominação de origem cujo registro é vedado pela lei, pois a disciplina legal da registrabilidade de indicações geográficas pressupõe a notoriedade da 
região na elaboração de produtos ou prestação de serviços, nos termos do art. 182 da LPI, o que não se evidencia nestes autos.

(BRASIL, STJ, RE 1.237.752)

No entanto, a indução ao consumidor ao erro pela utilização de marca semelhante, em atenção ao artigo 195 da Lei de Propriedade Industrial, pode ser configurada como concorrência desleal, mesmo não se tratando de Indicação de Procedência ou Denominação de Origem.

(...) 4. A marca mista é aquela constituída pela combinação de elementos nominativos e figurativos ou de elementos nominativos, cuja grafia se apresente de forma estilizada. Embora, em princípio, seja admissível o registro de uma mesma marca nominativa para produtos de classes diversas, o mesmo já não se dá com as marcas mistas, pois nessas a imagem de um produto passa necessariamente para o outro na percepção visual do consumidor, ou seja, no caso de marca mista, a parte figurativa e estilizada não pode coincidir com a do produto/serviço em confronto. $4.1 \mathrm{~A}$ proteção que o registro marcário visa a conferir ao titular da marca comercial é quanto ao seu conjunto. A despeito de o aproveitamento parasitário ser repelido pelo ordenamento jurídico pátrio, independentemente de registro, tal circunstância é de ser aferida a partir do cotejo, pelo conjunto, das marcas comerciais, sendo desimportante o elemento nominativo, individualmente considerado, sobretudo nas marcas de configuração mista, como é a que foi registrada pela autora. 4.2 No caso, apesar de as empresas (autora e ré) atuarem em ramos comerciais próximos, inocorreu a contrafação, senão a mera aplicação do vocábulo "Curitiba", que por si só não é capaz de ensejar o reconhecimento de utilização descabida de marca mista alheia. 5. Independentemente do registro da marca conter o radical comum, os atos dos concorrentes sempre poderão ser avaliados à luz das regras sobre concorrência desleal, pois o princípio da liberdade de concorrência - pedra angular do impulso e desenvolvimento do mercado - encontra baliza na lealdade negocial, dever decantado da boa-fé objetiva e que deve nortear o agir das empresas no âmbito comercial. 5.1 Com esteio no art. 195 da Lei de Propriedade Industrial (Lei $n^{\circ}$ 9.279/96), configura-se a concorrência desleal diante de imitação de marca passível de despertar confusão no consumidor, na medida em que a similitude visual de produtos/serviços, por meio da justaposição de cores e estilização coincidente, conjugada com a identidade de público-alvo, promove inquestionável tumulto por promover no consumidor a falsa idéia de estar adquirindo produto/serviço outro. $5.2 \mathrm{O}$ cenário fático-jurídico de concorrência desleal reclama o desenho de um comportamento - patrocinado por um operador econômico e diagnosticado no terreno negocial de certo produto ou serviço - que contrarie a condutadever que necessita ser observada no duelo pela clientela, via expedientes que desafiem sua idoneidade no mercado e, efetivamente, ou em potência, causem danos ao concorrente, uma vez que a caracterização da concorrência desleal/aproveitamento parasitário, que tem por base a noção de enriquecimento sem causa prevista no artigo 884 do Código Civil, é fundada nos elementos probatórios, devendo ser avaliada diante de cada caso concreto. 5.3 Não se afigura adequada a utilização do óbice da súmula 7/STJ, pois, além de a autora deter tão somente o direito exclusivo de uso da marca mista "Curitiba Multimarcas", que nenhum silogismo guarda com o nome comercial "Auto Shopping Curitiba", semântica ou figurativamente, haja vista a diferenciação clara entre os seus logotipos - o que afasta de plano o alegado uso indevido de marca alheia -, o próprio Tribunal de origem afirmou, categoricamente, ter a parte autora se descurado do munus 
processual de comprovar o fato constitutivo de seu direito (art. 333, I, do $\mathrm{CPC}$ ) no que tange aos eventuais prejuízos decorrentes da utilização do mesmo vocábulo "Curitiba" pela ré (confusão do público e proveito econômico). 5.4 O Tribunal a quo afirmou não ter restado provado o fato constitutivo do direito do autor relativamente à real existência de elementos fático-jurídicos caracterizadores de proveito parasitário que evidenciassem ter a empresa ré, por meio fraudulento, criado confusão entre serviços no mercado com o objetivo de desviar a clientela de outrem em proveito próprio ou alheio. 5.5 Face a aplicação da legislação correlata (incisos XIX e XXIII do art. 124, e inciso III e IV do art. 195 da Lei 9.279/96), em não tendo sido verificado, na presente hipótese, a existência de provas quanto à reprodução/imitação, no todo ou em parte, de marca alheia registrada, "suscetível de causar confusão ou associação com aquela marca alheia", inviável a manutenção do acórdão recorrido. 6. Recurso especial provido para reformar o acórdão recorrido e julgar improcedente a demanda. (BRASIL, STJ, RE 1.237.752)

\section{Consolidando desta forma o entendimento da Corte Superior, conforme se} observa no julgado colacionado:

AGRAVO REGIMENTAL EM RECURSO ESPECIAL. PROPRIEDADE INDUSTRIAL. AÇÃO ANULATÓRIA DE ATO ADMINISTRATIVO DENEGATÓRIO DE REGISTRO DE MARCA. ANTERIORIDADE IMPEDITIVA. PLEITO DE REGISTRO DA MARCA 'ÁGUAS PETRÓPOLIS PAULISTA' COM BASE NOS ARTIGOS 176 A 182 DA LPI. INDICAÇÃO GEOGRÁFICA. NÃO CONFIGURAÇÃO. REVISÃO. IMPOSSIBILIDADE. SÚMULA 7/STJ. 1. O Tribunal de origem, amparado na análise dos elementos fático-probatórios dos autos, concluiu pela identidade entre as marcas em tela e a possibilidade de confusão do público consumidor acerca da procedência dos produtos, entendendo não haver ilegalidade no ato administrativo do INPI que indeferiu o pedido de registro. Rever a decisão recorrida importaria necessariamente no reexame de provas, o que é defeso nesta fase recursal (Súmula 7-STJ) e impede o conhecimento do recurso. 2. Agravo regimental não provido. (BRASIL, STJ, AGRESP 1.185.538)

\section{Destaca-se também o seguinte julgado da Egrégia Corte Superior que reitera}

o caráter coletivo da Indicação Geográfica:

ARGUIÇÃO DE CONCORRÊNCIA DESLEAL. RECURSO ESPECIAL. APRECIAÇÃO, PELA JUSTIÇA ESTADUAL, DE MATÉRIA RELACIONADA À CONCORRÊNCIA DESLEAL, CONCERNENTE À UTILIZAÇÃO DE TERMO CONTIDO NA MARCA E NOME COMERCIAL DE SOCIEDADE EMPRESÁRIA CONCORRENTE. POSSIBILIDADE. EXCLUSIVIDADE DE UTILIZAÇÃO, EM MARCA, DE NOME DE RIO. DESCABIMENTO. POSSIBILIDADE DE CONFUSÃO AO CONSUMIDOR OU DESVIO DESLEAL DE CLIENTELA DESCARTADOS PELAS INSTÂNCIAS ORDINÁRIAS, COM BASE NOS ELEMENTOS CONTIDOS NOS AUTOS. REVISÃO DA DECISÃO, NA VIA ESPECIAL. INVIABILIDADE. EMBARGOS DE DECLARAÇÃO OPOSTOS COM FITO DE PREQUESTIONAMENTO. APLICAÇÃO DA MULTA PREVISTA NO ARTIGO 538 DO CPC. DESCABIMENTO. 1. A constatação da concorrência desleal demanda procedimento a ser realizado no âmbito do Judiciário, com contraditório, ampla defesa e possibilidade de produção de provas, inclusive pericial. 2. A 
titularidade para registro de indicação geográfica é, em regra, coletiva, não cabendo direito de exclusividade a quem obtém o registro de marca que a contenha. 3. De outra parte, embora a lei não vede o registro da marca contendo o termo "Sucuri", em tese é possível ser constatada a concorrência desleal, independentemente de malícia, caso apurada a semelhança de marcas adotadas por empresas concorrentes - a ponto de confundir o consumidor. Todavia, no caso as instâncias ordinárias, com base nos elementos existentes nos autos, descartaram a possibilidade de confusão ao consumidor quanto aos serviços prestados pelas partes, e consequente desvio desleal de clientela, por isso só se concebe a revisão da decisão recorrida por meio do reexame de provas, o que é obstado pela Súmula 7/STJ. 4. Recurso especial parcialmente provido, apenas para afastar a multa aplicada com base no artigo 538 do Código de Processo Civil. (BRASIL, STJ, RESP 1.092.676)

Conclui-se, desta forma, pela caracterização da identificação geográfica como direito coletivo, o que permite aos detentores uma série de inovações e vantagens, que vão desde ao fortalecimento empresarial a defesa dos direitos coletivos na esfera jurídica, em especial, com a possibilidade de atuação do órgão ministerial, tendo em vista o tema se enquadrar nas delimitações de ordem econômica e a proteção coletiva.

\section{REGISTROS E PERSPECTIVAS DAS INDICAÇÕES GEOGRÁFICAS DO ESTADO DE SANTA CATARINA}

Neste capítulo serão analisados os processos de Indicação Geográfica atinentes ao Estado de Santa Catarina, bem como, seus registros e perspectivas, delimitando os processos que se encontram em fase de criação e registro, além das Indicações Geográficas que já foram concedidas. Por fim, será realizado um comparativo entre as Indicações Geográficas do Estado de Santa Catarina, Rio Grande do Sul e Paraná.

\subsection{INDICAÇÕES GEOGRÁFICAS EM PROCESSO DE CRIAÇÃO}

O Projeto Desenvolvimento sustentável: Indicações Geográficas de produtos catarinenses, elaborado pela Universidade Federal de Santa Catarina realizou um estudo para apontar os principais mercados catarinenses com potencial elevado de obtenção de Indicação Geográfica.

Os cristais artesanais da região de Blumenau tiveram origem em 1946, com o empreendimento fundado nos moldes das cristaleiras alemãs. Sob a condução da 
empreendedora Alice, operários alemães se deslocaram para Blumenau com a finalidade de constituir a primeira cristaleira do sul do Brasil. Por se tratar de manufatura, os cristais possuem um grande destaque na economia local, inclusive atraindo turistas de diversas localidades para visitar os museus de cristais e a compra de produtos artesanais, devido a sua exclusividade.

Impulsionada pela Empresa de Pesquisa Agropecuária e Extensão Rural de Santa Catarina e pela Universidade Federal de Santa Catarina na segunda metade da década de 1980, as ostras cultivadas da região de Florianópolis detêm o título de maiores produtoras do país. $\mathrm{O}$ incentivo se deu para impulsionar a pesca artesanal e complementar a renda da população pesqueira na capital catarinense e entorno.

Outro produto que busca o reconhecimento da Indicação Geográfica tem origem nas produções do oeste catarinense voltados a produção de cárneos suínos. Considerando a expertise da região na produção dos embutidos e derivados, os produtores da região têm se organizado em busca de firmar um consenso para então proceder com a criação da entidade representativa e consequentemente da solicitação de indicação geográfica perante o INPI.

Ainda, a erva-mate da região do Planalto Norte Catarinense, que teve sua expansão no Brasil Colônia, com o início da produção no Paraná expandindo-se para o norte catarinense. O produto é tradicional na região sul do Brasil e o reconhecimento da Indicação Geográfica conferirá uma maior competitividade no mercado nacional e no internacional, sobretudo devido ao reconhecimento da distinção do produto na outorga da Indicação Geográfica.

Por fim, existem debates no Estado de Santa Catarina acerca de produtos com possível potencial para adquirirem a Indicação de Procedência ou a Denominação de Origem. A maçã da região de São Joaquim é um exemplo de Indicação Geográfica sendo estudado pela Epagri em parceria com o Sebrae/SC. O intuito de buscar o reconhecimento da maçã é uma forma de valorizar o produto, trazer reconhecimento nacional para o local, movimentar a economia, impulsionar o turismo e a gastronomia, uma vez que, as frutas daquela região possuem características diferentes das demais.

\subsection{INDICAÇÕES GEOGRÁFICAS EM PROCESSO DE REGISTRO}


No Projeto Desenvolvimento Sustentável: Indicações geográficas de produtos catarinenses, elaborado pela UFSC (Universidade Federal de Santa Catarina), retrata-se a situação do queijo artesanal serrano, que possui seu processo de concessão de Denominação de Origem conduzida pela Federação das Associações de Produtores de Queijo Artesanal Serrano de Santa Catarina e Rio Grande do Sul, em conjunto com o Ministério da Agricultura, Pecuária e Abastecimento.

O produto é fabricado de forma artesanal na serra catarinense, adotando-se a técnica de não cativeiro na criação dos animais fornecedores de leite, procedendo a extração do laticínio de forma campestre, o que imediatamente é conduzido aos processos caseiros de fabricação do queijo, combinado ao clima da região, que resulta em uma característica única ao produto final.

\subsection{INDICAÇÕES GEOGRÁFICAS REGISTRADAS}

Como exemplo de Indicação Geográfica consolidada no estado de Santa Catarina, remete-se aos vinhos dos Vales da Uva Goethe. Os colonizadores italianos se concentraram no sul catarinense realizaram o cultivo da uva oriunda dos Estados Unidos que era um enxerto de uvas europeias e estadunidenses, sendo que o fruto se adaptou bem ao clima frio da região. Constituída a Associação dos Produtores da Uva e do Vinho Goethe na Região de Urussanga (Pro-Goethe), efetuou-se o pedido para registro da Indicação Geográfica, sendo concedida no ano de 2011, abrangendo os municípios de Urussanga, Pedras Grandes, Morro da Fumaça, Cocal do Sul, Nova Veneza, Içara, Treze de Maio e Orleans.

Ainda, a Associação dos Bananicultores da Região de Corupá também entrou com o pedido para o reconhecimento de Indicação de Procedência. Conhecidas como "Banana de Corupá", elas têm como característica principal seu doce natural e único devido as condições climáticas do local. Este é o registro mais recente no Estado de Santa Catarina, visto que, foi concedido na data de 28 de agosto de 2018.

\subsection{PERSPECTIVAS DAS INDICAÇÕES GEOGRÁFICAS EM SANTA CATARINA}

Tendo em vista as informações acima, apenas duas regiões de Santa Catarina possuem produtos com o reconhecimento da Indicação Geográfica concedidos, além do Queijo Artesanal Serrano em fase de depósito. 
Fazendo uma breve análise, os pedidos de Santa Catarina depositados e os registros já concedidos por parte do Instituto Nacional da Propriedade Industrial são pouquíssimos se comparados aos do Estado do Rio Grande do Sul e do Paraná, por exemplo.

No Rio Grande do Sul, existem dez regiões que já obtém concedido o pedido de Indicação Geográfica para uma variedade de produtos, outras duas regiões possuem pedidos que foram depositados, mas ainda não obtiveram êxito. Já no Estado do Paraná, seis localidades possuem produtos com a Indicação Geográfica reconhecida, restando outras três regiões com pedidos em fase de depósito e uma em fase de exigência.

Os produtos com a Indicação Geográfica reconhecida no Estado do Rio Grande do Sul e do Paraná são extremamente simples e existem em qualquer região, mas possuem a Indicação Geográfica devido as suas qualidades únicas e peculiares, que graças as Associações de Produtores, conseguiram esse reconhecimento nacional para seus produtos, em parceria com o Instituto Nacional da Propriedade Industrial. Neste sentido, segue abaixo gráfico comparativo dos registros já concedidos e os que se encontram em andamento da Região Sul.

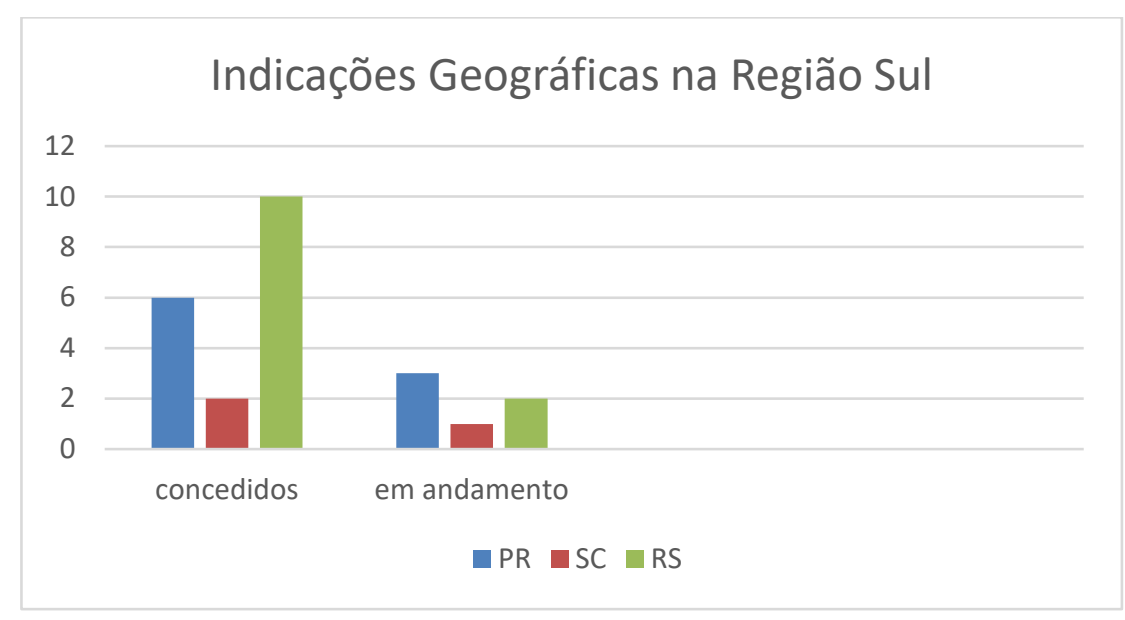

Dados extraídos no sítio eletrônico do INPI

Assim, apesar de haver diversos produtos em fase de criação, percebe-se que o Estado de Santa Catarina não pode ser considerado um centro de referência para as Indicações Geográficas brasileiras, uma vez que, existem poucos registros de Indicação de Procedência e Denominação de Origem já concedidos. 
Por fim, a partir da análise realizada, pode-se pensar em uma possível falta de incentivo por parte do Governo e do próprio Estado para com as Indicações Geográficas e as respectivas Associações de Produtores. Se as Indicações Geográficas catarinenses forem realmente incentivadas, haverá um grande reconhecimento nacional e internacional para nosso Estado, uma vez que, os produtos que se encontram em fase de criação possuem um enorme potencial de reconhecimento, o que acabaria atraindo cada vez mais turistas e movimentando ainda mais a economia para Santa Catarina.

\section{CONCLUSÃO}

Nota-se que o tema abordado é pouco conhecido na sociedade, sobretudo para aqueles que atuam na área jurídica. Ainda assim, as Indicações Geográficas possuem proteção no âmbito da Propriedade Industrial e são de grande importância para a economia, pois valorizam produtos agroalimentares, artesanato, entre muitos outros, além de atrair turistas para as regiões que buscaram o registro, uma vez que, possuir o selo de Indicação Geográfica nos produtos acaba se tornando um atrativo a mais, por ser algo com características e qualidades específicas de cada região, o que as tornam únicas.

Para que se pudesse responder à problemática da pesquisa, o artigo fora divido em três etapas. A primeira delas falou acerca da Propriedade Intelectual, Propriedade Industrial e seus desdobramentos, para se chegar à Indicação Geográfica.

No item seguinte, abordaram-se os conceitos sobre Indicação Geográfica, sobretudo com relação às Denominações de Origem e Indicações de Procedência, na qualidade de espécies de Indicações Geográficas.

Por fim, no último tópico, foram analisados os dados relacionados aos registros de regiões que buscassem a proteção jurídica relacionada ao tema. A pesquisa buscou analisar a Região Sul, eis que a problemática envolvia as perspectivas do Estado de Santa Catarina no que se refere às Indicações Geográficas.

Assim, no que se refere as Indicações Geográficas Catarinenses, foi possível identificar que existem poucos registros concedidos se comparados aos de outros estados, como foi brevemente analisado o Estado do Rio Grande do Sul e do PIDCC, Aracaju/Se, Ano VIII, Volume 13 no 02, p.086 a 114 Jul/2019 | www.pidcc.com.br 
Paraná. Assim, pode-se relacionar isso a falta de incentivo por parte do Governo, o que acaba prejudicando a economia catarinense, a qual cresceria ainda mais se os potenciais de Indicações Geográficas tivessem o devido apoio por parte de todos os responsáveis.

Desta forma, as Indicações Geográficas regulamentadas pela Lei da Propriedade Industrial apesar da pouca regulamentação são suficientes para gerenciar perfeitamente todo o conteúdo regulamentado, ao passo que os problemas decorrentes dessa temática se operam no campo executivo, sobretudo pela falta de apoio governamental e na morosidade dos reconhecimentos das Indicações Geográficas.

\section{REFERÊNCIAS}

BARBOSA, Denis Borges. Tratado da Propriedade Intelectual. Rio de Janeiro: Editora Lumen Juris, 2013.

BARROS, Carla Eugenia Caldas. Manual de Direito da Propriedade Intelectual, Evocati: Aracaju, 2007.

BASSO, Maristela; POLIDO, Fabrício; JUNIOR, Edson Beas Rodrigues.

Propriedade intelectual: legislação e tratados internacionais. 1. Ed. São Paulo: Editora Atlas S.A, 2007. 636 p.

BLASI, Gabriel Di. A Propriedade Industrial: Os sistemas de marcas, patentes e desenhos industriais analisados a partir da Lei $n^{\circ}$ 9.279, de 14 de maio de 1996. 3. ed. Rio de Janeiro: Editora Forense, 2010. 534 p.

BRASIL. Constituição Federal do. Art. 5, inc. XXIX da Constituição Federal de 88. Disponível em: https://www.jusbrasil.com.br/topicos/10729907/inciso-xxix-doartigo-5-da-constituicao-federal-de-1988. Acesso em: 04 abr. 2018.

BRASIL. Lei n. 9.279, de 14 de maio de 1996. Regula direitos e obrigações relativos à propriedade industrial. Disponível em:

http://www.planalto.gov.br/ccivil_03/leis/L9279.htm. Acesso em: 29 set. 2018.

BRASIL, Superior Tribunal de Justiça. Agravo Regimental no Recurso Especial n 1.185.538, Ministro Relator Luis Felipe Salomão, Brasília, DF, 04 de dezembro de 2012.

BRASIL. Recurso Especial $\mathbf{n}^{\circ}$ 1.092.676, Ministro Relator Luis Felipe Salomão, Brasília, DF, 15 de maio de 2012.

BRASIL. Recurso Especial $\mathbf{n}^{\mathbf{0}}$ 1.237.752, Ministro Relator Luis Felipe Salomão, Brasília, DF, 05 de março de 2015. 
COORDENAÇÃO GERAL DE COMUNICAÇÃO SOCIAL. Guia básico de indicação geográfica. 2018. Disponível em: http://www.inpi.gov.br/menu-servicos/indicacaogeografica. Acesso em: 17 set. 2018.

COORDENAÇÃO GERAL DE COMUNICAÇÃO SOCIAL. Indicação Geográfica no Brasil. 2015. Disponivel em: http://www.inpi.gov.br/menu-servicos/indicacaogeografica/indicacao-geografica-no-brasil. Acesso em: 17 set. 2018.

DA COSTA, Dahyana Simam Carvalho. Propriedade Industrial. Disponível em https://www.boletimjuridico.com.br/doutrina/texto.asp?id=834. Acesso em: 04 abr. 2018.

EPAGRI. Indicação Geográfica para a maçã da região de São Joaquim entra em debate nesta sexta-feira. 2018. Disponível em: https://serrainfoco.com.br/indicacaogeografica-para-maca-da-regiao-de-sao-joaquim-entra-em-debate-nesta-sexta-feira/. Acesso em: 14 out. 2018.

IBGE (Instituto Brasileiro de Geografia e Estatística). Os aspectos relevantes dos nomes geográficos e os procedimentos de carga BNGB (Banco de nomes geográficos no Brasil). Rio de Janeiro: IBGE, 2008. Disponível em: http://www.ngb.ibge.gov.br/App_Doc/APOSTILA_ASPECTOS\%20DA\%20COLETA\% 20DE\%20NOMES\%20GEOGRAFICOS_jUL2008_REVISADO_GRACIOSA_VITOR. pdf. Acesso em: 29 set. 2018.

INPI (instituto Nacional da Propriedade Industrial). Documentos necessários para pedido de IG. 2015. Disponível em: http://www.inpi.gov.br/menu-servicos/indicacaogeografica/documentos-necessarios-para-pedido-de-ig. Acesso em: 29 set. 2018.

INPI (instituto Nacional da Propriedade Industrial). Instrução Normativa n. 25, de 28 de agosto de 2013. Estabelece as condições para o registro das indicações geográficas. Disponível em: http://www.inpi.gov.br/legislacao1/in_25_21_de_agosto_de_2013.pdf. Acesso em: 29 set. 2018.

ITAMARATY. O Acordo TRIPS: um panorama. 2018. Disponível em: http://delbrasomc.itamaraty.gov.br/pt-br/acordo_trips.xml. Acesso em: 29 set. 2018.

Lei $\mathrm{n}^{\circ} \mathbf{9 . 2 7 9}$, de 14 de maio de 1996. A proteção dos direitos relativos à propriedade industrial, considerando o seu interesse social e o desenvolvimento tecnológico e econômico do País, efetua-se mediante. Disponível em: http://www.planalto.gov.br/ccivil_03/leis/L9279.htm. Acesso em: 04 abr. 2018.

LOCATELLI, Liliana. Indicações Geográficas. Rio de Janeiro: Editora Lumen Juris, 2016.

MORAES, Guilherme Peña de. Curso de Direito Constitucional, $9^{a}$ edição. São Paulo: Atlas,2017, p. 225.

OMC (Organização Mundial do Comércio). Acordo sobre Aspectos dos Direitos de Propriedade Intelectual Relacionados ao Comércio, de 15 de abril de 1994. Disponível em: http://www.nedac.com.br/pdf/ac_trips.pdf. Acesso em: 29 set. 2018.

PAESANI, Liliana Minardi. Manual de Propriedade Intelectual, $2^{\mathrm{a}}$ edição. São Paulo: Atlas, 2015. 
INDICAÇÕES GEOGRÁFICAS: REGISTROS E PERSPECTIVAS NO ESTADO DE SANTA CATARINA E-ISSN 2316-8080

UFSC (Universidade Federal de Santa Catarina). Indicações Geográficas Catarinenses. 2015. Disponível em:

http://docs.wixstatic.com/ugd/cc0e91_9ca37624af2148578bbda74e73a0b1be.pdf. Acesso em: 10 out. 2018.

\section{ANEXOS}




\begin{tabular}{|c|c|c|c|c|c|c|c|c|c|}
\hline & \multicolumn{9}{|c|}{ PLANILHA DE ACOMPANHAMENTO DOS PEDIDOS/REGISTROS DE INDICAÇÖES GEOGRÁFICAS } \\
\hline & $\mathbf{N}^{\circ}$ & Indicação Geográfica & Espécie & Depósito & Requerente & País/UF & Produto/serviço & Situação & $\begin{array}{l}\text { Publicaçáo } \\
\text { na RPI }\end{array}$ \\
\hline 1 & IG970001 & \begin{tabular}{|l|l|l|l|l} 
Parma & \\
\end{tabular} & DO & $22 / 08 / 1997$ & $\begin{array}{l}\text { Consorzio del Prosciutto di } \\
\text { Parma }\end{array}$ & IT & Presunto & $\begin{array}{c}\text { Exigência em } \\
\text { recurso CGREC }\end{array}$ & $\begin{array}{c}2216, \text { de } \\
25 / 06 / 2013\end{array}$ \\
\hline 2 & IG970002 & $\begin{array}{l}\text { Regiäo dos Vinhos } \\
\text { Verdes }\end{array}$ & $\overline{D O}$ & 19/09/1997 & $\begin{array}{l}\text { Comissão de Viticultura da } \\
\text { Região dos Vinhos Verdes }\end{array}$ & PT & Vinhos & $\begin{array}{l}\text { Registro concedido } \\
\text { (395) }\end{array}$ & $\begin{array}{c}1492, \text { de } \\
10 / 08 / 1999\end{array}$ \\
\hline 3 & IG980001 & Cognac & DO & 12/03/1998 & \begin{tabular}{|l|} 
Bureau National \\
Interprofessionel du Cognac
\end{tabular} & FR & $\begin{array}{l}\text { Destilado vínico ou aguardente de } \\
\text { vinho }\end{array}$ & $\begin{array}{l}\text { Registro concedido } \\
\text { (395) }\end{array}$ & $\begin{array}{c}1527, \mathrm{de} \\
11 / 04 / 2000\end{array}$ \\
\hline 4 & IG980002 & Cerrado & DO & $20 / 05 / 1998$ & $\begin{array}{l}\text { Conselho das Associações dos } \\
\text { Cafeicultores do Cerrado }\end{array}$ & BR/MG & Café & Arquivado (325) & $\begin{array}{c}1479, \text { de } \\
11 / 05 / 1999\end{array}$ \\
\hline 5 & IG980003 & San Daniele & DO & 20/10/1998 & \begin{tabular}{|l|}
$\begin{array}{l}\text { Consorzio del Prosciutto di San } \\
\text { Daniele }\end{array}$ \\
\end{tabular} & IT & $\begin{array}{l}\text { Coxas de suinos frescas, presunto } \\
\text { defumado e crú }\end{array}$ & $\begin{array}{c}\text { Registro concedido } \\
\text { (395) }\end{array}$ & $\begin{array}{c}1996, \text { de } \\
07 / 04 / 2009\end{array}$ \\
\hline 6 & IG990001 & $\begin{array}{l}\text { Regiäo do Cerrado } \\
\text { Mineiro }\end{array}$ & IP & $28 / 01 / 1999$ & $\begin{array}{l}\text { Cons. das Ass. dos } \\
\text { Cafeicultores do Cerado - } \\
\text { CACCER }\end{array}$ & $\mathrm{BR} / \mathrm{MG}$ & Café & $\begin{array}{l}\text { Registro concedido } \\
\text { (395) }\end{array}$ & $\begin{array}{l}1797 \text {, de } \\
14 / 04 / 2005\end{array}$ \\
\hline 7 & IG200001 & $\begin{array}{l}\text { Padana (DO Grana } \\
\text { Padano) }\end{array}$ & DO & $10 / 02 / 2000$ & $\begin{array}{l}\text { Consorzio Per La Tutela Del } \\
\text { Formaggio Grana Padano }\end{array}$ & IT & Queijo & $\begin{array}{l}\text { Pedido publicado } \\
\text { (335) }\end{array}$ & $\begin{array}{c}1640, \mathrm{de} \\
11 / 06 / 2002\end{array}$ \\
\hline 8 & IG200002 & Vale dos Vinhedos & IP & $06 / 07 / 2000$ & $\begin{array}{l}\text { A. P. de Vinhos Finos do Vale } \\
\text { dos Vinhedos - APROVALE }\end{array}$ & BR/RS & Vinho tinto, branco e espumantes & $\begin{array}{l}\text { Registro concedido } \\
\text { (395) }\end{array}$ & $\begin{array}{c}1663, \text { de } \\
19 / 11 / 2002 \\
\end{array}$ \\
\hline 9 & IG200101 & Franciacorta & DO & 05/06/2001 & $\begin{array}{l}\text { Consorzio Per la Tutela Del } \\
\text { Franciacorta }\end{array}$ & IT & $\begin{array}{l}\text { Vinhos, vinhos espumantes e } \\
\text { bebidas alcoólicas }\end{array}$ & $\begin{array}{c}\text { Registro concedido } \\
\text { (395) }\end{array}$ & $\begin{array}{c}1711, \text { de } \\
21 / 10 / 2003\end{array}$ \\
\hline 10 & IG200102 & Roquefort & DO & $21 / 09 / 2001$ & \begin{tabular}{|l|} 
Conf. Gen.des Prod. Lait de \\
Brebis et des Ind.de Roquefort
\end{tabular} & FR & Queijos & $\begin{array}{l}\text { Registro concedido } \\
\text { (395) }\end{array}$ & $\begin{array}{c}2212, \mathrm{de} \\
28 / 05 / 2013\end{array}$ \\
\hline 11 & IG200201 & Solingen & IP & $25 / 04 / 2002$ & $\begin{array}{l}\text { Ind.-End Handelskamm } \\
\text { Wuppertal-Solingen-Remscheid }\end{array}$ & $\mathrm{DE}$ & Artigos de Cutelaria & $\begin{array}{l}\text { Arquivado (325) } \\
\text { Pedido em revisão }\end{array}$ & $\begin{array}{l}1912, \text { de } \\
28 / 08 / 2007\end{array}$ \\
\hline 12 & IG200202 & Asti & $\overline{D O}$ & 19/06/2002 & Consorzio Per la Tutela Dell'Asti & IT & Vinhos & Indeferido (375) & $\begin{array}{c}1946, \text { de } \\
22 / 04 / 2008 \\
\end{array}$ \\
\hline 13 & IG200203 & Terras Altas & IP & $12 / 09 / 2002$ & $\begin{array}{l}\text { Coop. Reg. dos Cafeicult. de } \\
\text { São Sebastião do Paraiso Ltda }\end{array}$ & $\mathrm{BR} / \mathrm{MG}$ & Café & Indeferido (375) & $\begin{array}{c}1885, \text { de } \\
21 / 02 / 2007\end{array}$ \\
\hline 14 & IG200204 & Alto Paraiso & $\mathbb{I P}$ & $12 / 09 / 2002$ & $\begin{array}{l}\text { Coop. Reg. dos Cafeicult. de } \\
\text { São Sebastião do Paraiso Ltda }\end{array}$ & $\overline{B R / M G}$ & Café & Indeferido (375) & $\begin{array}{c}1885, \mathrm{de} \\
21 / 02 / 2007\end{array}$ \\
\hline 15 & IG200401 & \begin{tabular}{|l|} 
Água Mineral Natural \\
Terra Alta
\end{tabular} & IP & 05/01/2004 & $\begin{array}{l}\text { Aguas Cristalinas Ind. e Com. } \\
\text { de Prod. Alimenticios Ltda }\end{array}$ & BR/PA & $\begin{array}{l}\text { Serviços auxiliares ao comercio de } \\
\text { águas minerais e gasosas } \\
\text { engarrafadas }\end{array}$ & Arquivado (325) & $\begin{array}{l}\text { 1853, de } \\
11 / 07 / 2006\end{array}$ \\
\hline 16 & IG200402 & $\begin{array}{l}\text { Água Mineral Natural } \\
\text { Terra Alta }\end{array}$ & IP & 05/01/2004 & $\begin{array}{l}\text { Aguas Cristalinas Ind. e Com. } \\
\text { de Prod. Alimenticios Ltda }\end{array}$ & $\mathrm{BR} / \mathrm{PA}$ & $\begin{array}{l}\text { Agguas minerais e gasosas, } \\
\text { engarrafamento }\end{array}$ & Arquivado (325) & $\begin{array}{c}1853, \mathrm{de} \\
11 / 07 / 2006\end{array}$ \\
\hline 17 & IG200403 & \begin{tabular}{|l|} 
Regiäo do Seridó do \\
Estado da Paraiba \\
\end{tabular} & DO & $01 / 07 / 2004$ & \begin{tabular}{|l|}
$\begin{array}{l}\text { Companhia de } \\
\text { Desenvolvimento. da Paraiba }\end{array}$ \\
\end{tabular} & $\mathrm{BR} / \mathrm{PB}$ & $\begin{array}{l}\text { Algodão colorido BRS- Verde, BRS } \\
\text { 200-Marrom }\end{array}$ & Arquivado (325) & $\begin{array}{c}1877, \mathrm{de} \\
26 / 12 / 2006 \\
\end{array}$ \\
\hline 18 & $\begin{array}{ll}\text { IG200404 } \\
\end{array}$ & $\begin{array}{l}\text { Santa Rita do Sapucaí - } \\
\text { O Vale da Eletrônica }\end{array}$ & $\mathbb{I P}$ & 20/12/2004 & $\begin{array}{l}\text { Sindicato das Industrias de } \\
\text { Aparelhos eletrônicos, } \\
\text { eletrônicos e similares do Vale } \\
\text { Eletrônica }\end{array}$ & $\mathrm{BR} / \mathrm{MG}$ & $\begin{array}{l}\text { Equipamentos eletrônicos e de } \\
\text { telecomunicaçăo }\end{array}$ & Arquivado (325) & $\begin{array}{c}1853, \text { de } \\
11 / 07 / 2006\end{array}$ \\
\hline
\end{tabular}

\begin{tabular}{|c|c|c|c|c|c|c|c|c|c|}
\hline 19 & IG200405 & $\begin{array}{l}\text { Regiäo do Municipio de } \\
\text { Serra Negra do Estado } \\
\text { de São Paulo }\end{array}$ & IP & $28 / 12 / 2004$ & \begin{tabular}{|l|} 
Prefeitura Municipal da Estância \\
Hidromineral de Serra Negra
\end{tabular} & BR/SP & \begin{tabular}{|l} 
Extração/Exploração de Agua \\
Mineral, comércio e industria de \\
malhas, artesanato, hoteleira, \\
balneário e turismo
\end{tabular} & Arquivado (325) & $\begin{array}{c}1877, \text { de } \\
26 / 12 / 2006\end{array}$ \\
\hline 20 & IG200501 & \begin{tabular}{|l} 
Pampa Gaúcho da \\
Campanha Meridional
\end{tabular} & IP & $08 / 08 / 2005$ & $\begin{array}{l}\text { Ass. Prod. Carne do Pampa } \\
\text { Gaúcho da Campanha } \\
\text { Meridional }\end{array}$ & $\mathrm{BR} / \mathrm{RS}$ & \begin{tabular}{|l|} 
Carne Bovina e seus derivados \\
\end{tabular} & $\begin{array}{l}\text { Registro concedido } \\
\text { (395) }\end{array}$ & $\begin{array}{c}\text { 1875, de } \\
12 / 12 / 2006\end{array}$ \\
\hline 21 & IG200601 & \begin{tabular}{|l|} 
Chianti Classico \\
\end{tabular} & $\overline{\mathrm{DO}}$ & $22 / 03 / 2006$ & Consorzio Vino Chiant Classico & IT & Vinhos & $\begin{array}{c}\text { Arquivado (325) } \\
\text { Pedido em revisão }\end{array}$ & $\begin{array}{c}1912, \mathrm{de} \\
28 / 08 / 2007\end{array}$ \\
\hline 22 & IG200602 & Paraty & IP & $27 / 11 / 2006$ & \begin{tabular}{|l|} 
Ass. dos Produtores e Amigos \\
da Cachaça Artesanal de Paraty
\end{tabular} & BR/RJ & $\begin{array}{l}\text { Produção de aguardentes, tipo } \\
\text { cachaça e aguardente composta } \\
\text { azulada a }\end{array}$ & $\begin{array}{l}\text { Registro concedido } \\
\text { (395) }\end{array}$ & $\begin{array}{c}\text { 1905, de } \\
10 / 07 / 2007\end{array}$ \\
\hline 23 & IG200701 & $\begin{array}{l}\text { Vale do Submédio São } \\
\text { Francisco }\end{array}$ & IP & $31 / 08 / 2007$ & $\begin{array}{l}\text { Conselho da Uniäo das Ass. e } \\
\text { Coop.dos Produtores de Uvas } \\
\text { de Mesa e Mangas do Vale do } \\
\text { Submédio São Francisco - }\end{array}$ & $\mathrm{BR} / \mathrm{BA} / \mathrm{PE}$ & Uvas de Mesa e Manga & $\begin{array}{l}\text { Registro concedido } \\
\text { (395) }\end{array}$ & $\begin{array}{c}\text { 2009, de } \\
07 / 07 / 2009\end{array}$ \\
\hline 24 & IG200702 & Vale do Sinos & IP & $14 / 09 / 2007$ & \begin{tabular}{l|} 
Associação das Industrias de \\
Cortumes do Rio Grande do Sul \\
AICSUL
\end{tabular} & $\mathrm{BR} / \mathrm{RS}$ & Couro Acabado & $\begin{array}{l}\text { Registro concedido } \\
\text { (395) }\end{array}$ & $\begin{array}{l}\text { 2002, de } \\
19 / 05 / 2009\end{array}$ \\
\hline \multirow[b]{2}{*}{25} & \multirow[t]{2}{*}{ IG200703 } & \multirow[t]{2}{*}{ Alta Mogiana } & \multirow[t]{2}{*}{ IP } & \multirow[t]{2}{*}{$26 / 09 / 2007$} & \multirow{2}{*}{\begin{tabular}{|l|} 
Associação dos Produtores de \\
Cafés Especiais da Alta \\
Mogiana
\end{tabular}} & \multirow[t]{2}{*}{$\mathrm{BR} / \mathrm{SP}$} & \multirow[t]{2}{*}{ Café } & $\begin{array}{l}\text { Registro concedido } \\
\text { (395) }\end{array}$ & $\begin{array}{c}2228, \mathrm{de} \\
17 / 09 / 2013\end{array}$ \\
\hline & & & & & & & & $\begin{array}{c}\text { Petição não } \\
\text { conhecida }(410)\end{array}$ & $\begin{array}{l}\text { 2327, de } \\
11 / 08 / 2015\end{array}$ \\
\hline \multirow{2}{*}{26} & \multirow[t]{2}{*}{ IG200704 } & \multirow{2}{*}{$\begin{array}{l}\text { Regiäo da Serra da } \\
\text { Mantiqueira de Minas } \\
\text { Gerais }\end{array}$} & \multirow[t]{2}{*}{$\mathbb{I P}$} & \multirow[t]{2}{*}{$03 / 10 / 2007$} & \multirow[t]{2}{*}{$\begin{array}{l}\text { Associação dos Produtores de } \\
\text { Café da Mantiqueira }\end{array}$} & \multirow[t]{2}{*}{ BR/MG } & \multirow[t]{2}{*}{ Café } & $\begin{array}{l}\text { Registro concedido } \\
\text { (395) }\end{array}$ & $\begin{array}{c}2108, \text { de } \\
31 / 05 / 2011\end{array}$ \\
\hline & & & & & & & & $\begin{array}{c}\text { Petição não } \\
\text { conhecida (410) }\end{array}$ & $\begin{array}{c}2326, \mathrm{de} \\
04 / 08 / 2015\end{array}$ \\
\hline 27 & IG200801 & Litoral Norte Gaúcho & DO & $28 / 01 / 2008$ & $\begin{array}{l}\text { Associaçăa dos Produtores de } \\
\text { Arroz do Litoral Norte Gaúcho - } \\
\text { APROARROZ }\end{array}$ & BR/RS & Arroz & $\begin{array}{c}\text { Registro concedido } \\
\text { (395) }\end{array}$ & $\begin{array}{c}2068 \text {, de } \\
24 / 08 / 2010\end{array}$ \\
\hline \multirow[b]{2}{*}{28} & \multirow[t]{2}{*}{ IG200802 } & \multirow[t]{2}{*}{ Tequila } & \multirow[t]{2}{*}{ DO } & \multirow[t]{2}{*}{$01 / 08 / 2008$} & \multirow[t]{2}{*}{$\begin{array}{l}\text { Consejo Regulador del Tequila } \\
\text { A C. }\end{array}$} & \multirow[t]{2}{*}{$M X$} & \multirow{2}{*}{$\begin{array}{l}\text { Bebida alcoólica regional obtida por } \\
\text { destilação de mostos }(. . .) \text { de agave } \\
\text { tequilana weber, variedade azul }\end{array}$} & $\begin{array}{c}\text { Pedido publicado } \\
\text { (335) }\end{array}$ & $\begin{array}{c}2042, \text { de } \\
23 / 02 / 2010 \\
\end{array}$ \\
\hline & & & & & & & & $\begin{array}{c}\text { Petição não } \\
\text { conhecida (410) }\end{array}$ & $\begin{array}{l}\text { 2127, de } \\
04 / 10 / 2011\end{array}$ \\
\hline 29 & IG200803 & Pinto Bandeira & IP & $07 / 10 / 2008$ & \begin{tabular}{|l|} 
Associação dos Produtores de \\
Vinhos Finos de Pinto Bandeira \\
ASPROVINHO
\end{tabular} & $\mathrm{BR} / \mathrm{RS}$ & Vinhos tinto, brancos e espumantes & $\begin{array}{l}\text { Registro concedido } \\
\text { (395) }\end{array}$ & $\begin{array}{l}2062 \text {, de } \\
13 / 07 / 2010\end{array}$ \\
\hline 30 & IG200804 & Conegliano & DO & $18 / 11 / 2008$ & $\begin{array}{l}\text { Consorzio Tutela Vino Prosecco } \\
\text { di Conegliano-Valdobbiadene }\end{array}$ & IT & $\begin{array}{l}\text { Prosecco di Conegliano- } \\
\text { Valdobbiadene }\end{array}$ & Exigência (305) & $\begin{array}{c}\text { 2040, de } \\
09 / 02 / 2010\end{array}$ \\
\hline 31 & IG200901 & Pelotas & IP & $12 / 03 / 2009$ & $\begin{array}{l}\text { Associação dos Produtores de } \\
\text { Doces de Pelotas }\end{array}$ & BR/RS & $\begin{array}{l}\text { Doces tradicionais e confeitaria de } \\
\text { frutas }\end{array}$ & $\begin{array}{l}\text { Registro concedido } \\
\text { (395) }\end{array}$ & $\begin{array}{c}2121, \mathrm{de} \\
30 / 08 / 2011\end{array}$ \\
\hline 32 & IG200902 & \begin{tabular}{|l|} 
Regiäo do Jalapão do \\
Estado do Tocantins
\end{tabular} & IP & $18 / 05 / 2009$ & \begin{tabular}{|l|} 
Associação dos Artesãos em \\
Capim Dourado da Região do \\
Jalapão do Estado de Tocantins \\
- AREJA
\end{tabular} & $\mathrm{BR} / \mathrm{TO}$ & Artesanato em Capim Dourado & $\begin{array}{l}\text { Registro concedido } \\
\text { (395) }\end{array}$ & $\begin{array}{c}2121 \text {, de } \\
30 / 08 / 2011\end{array}$ \\
\hline
\end{tabular}




\begin{tabular}{|c|c|c|c|c|c|c|c|c|c|}
\hline 33 & IG200903 & \begin{tabular}{|l} 
Norte Pioneiro do \\
Paraná
\end{tabular} & $\overline{I P}$ & $26 / 03 / 2009$ & $\begin{array}{l}\text { Associação dos Cafés Especiais } \\
\text { do Norte Pioneiro do Paraná }\end{array}$ & BR/PR & $\begin{array}{l}\text { Café verde em grão e industrializado } \\
\text { em grão e ou moido }\end{array}$ & $\begin{array}{l}\text { Registro concedido } \\
\text { (395) }\end{array}$ & $\begin{array}{c}2177, \text { de } \\
25 / 09 / 2012\end{array}$ \\
\hline 34 & IG200904 & Paraiba & $\overline{I P}$ & $27 / 07 / 2009$ & $\begin{array}{l}\text { Cooperativa de produção textil } \\
\text { de afins do algodão- } \\
\text { COOPNATURAL }\end{array}$ & BR/PB & $\begin{array}{l}\text { Têxteis de algodão naturalmente } \\
\text { colorido }\end{array}$ & $\begin{array}{l}\text { Registro concedido } \\
\text { (395) }\end{array}$ & $\begin{array}{l}2180, \text { de } \\
16 / 10 / 2012\end{array}$ \\
\hline 35 & IG200905 & Douro & $\overline{\mathrm{DO}}$ & $20 / 11 / 2009$ & $\begin{array}{l}\text { Instituto dos Vinhos do Douro e } \\
\text { do Porto }\end{array}$ & PT & Vinho & $\begin{array}{l}\text { Pedido publicado } \\
\text { (335) }\end{array}$ & $\begin{array}{c}2075, \mathrm{de} \\
13 / 10 / 2010\end{array}$ \\
\hline 36 & IG200906 & Porto & DO & $20 / 11 / 2009$ & $\begin{array}{l}\text { Instituto dos Vinhos do Douro e } \\
\text { do Porto }\end{array}$ & PT & Vinho generoso (vinho licoroso) & Arquivado (325) & $\begin{array}{c}2079, \text { de } \\
09 / 11 / 2010\end{array}$ \\
\hline 37 & IG200907 & Costa Negra & $\overline{\mathrm{DO}}$ & $03 / 10 / 2009$ & $\begin{array}{l}\text { Associação dos Carcinicultores } \\
\text { da Costa Negra - ACCN }\end{array}$ & $\mathrm{BR} / \mathrm{CE}$ & $\begin{array}{l}\text { Camaröes marinhos cultivados da } \\
\text { espécie Litopenaeus Vannamei }\end{array}$ & $\begin{array}{l}\text { Registro concedido } \\
\text { (395) }\end{array}$ & $\begin{array}{l}2119, \text { de } \\
16 / 08 / 2011\end{array}$ \\
\hline 38 & IG200908 & Regiäo de Salinas & $\overline{I P}$ & $22 / 12 / 2009$ & $\begin{array}{l}\text { Associação dos Produtores de } \\
\text { Cachaça de Salinas }\end{array}$ & $\overline{B R / M G}$ & Aguardente de cana tipo Cachaça & $\begin{array}{l}\text { Registro concedido } \\
\text { (395) }\end{array}$ & $\begin{array}{c}2180, \mathrm{de} \\
16 / 10 / 2012\end{array}$ \\
\hline 39 & IG200909 & Linhares & IP & $22 / 12 / 2009$ & $\begin{array}{l}\text { Associaçäo dos Cacauicultores } \\
\text { de Linhares }\end{array}$ & BR/ES & Cacau em amêndoas & $\begin{array}{l}\text { Registro concedido } \\
\text { (395) }\end{array}$ & $\begin{array}{c}2169, \mathrm{de} \\
31 / 07 / 2012\end{array}$ \\
\hline 40 & IG200910 & Barbaresco & $\overline{\mathrm{DO}}$ & $24 / 12 / 2009$ & $\begin{array}{l}\text { Consorzio di Tutela Barolo } \\
\text { Barbaresco Alba Langhe e } \\
\text { Roero }\end{array}$ & IT & Vinhos & Exigência (305) & $\begin{array}{c}2072, \text { de } \\
21 / 09 / 2010\end{array}$ \\
\hline 41 & IG200911 & Barolo & $\overline{\mathrm{DO}}$ & $24 / 12 / 2009$ & $\begin{array}{l}\text { Consorzio di Tutela Barolo } \\
\text { Barbaresco Alba Langhe e } \\
\text { Roero }\end{array}$ & IT & Vinhos & Exigência (305) & $\begin{array}{c}2072, \text { de } \\
21 / 09 / 2010\end{array}$ \\
\hline 42 & IG201001 & Serro & IP & $16 / 04 / 2010$ & \begin{tabular}{|l|} 
Associação do Produtores \\
Artesanais de Queijo do Serro \\
\end{tabular} & BR/MG & Queijo minas artesanal do serro & $\begin{array}{l}\text { Registro concedido } \\
\text { (395) }\end{array}$ & $\begin{array}{c}2136, \text { de } \\
13 / 12 / 2011 \\
\end{array}$ \\
\hline 43 & IG201002 & Canastra & $\mathbb{I P}$ & $16 / 04 / 2010$ & $\begin{array}{l}\text { Associaçäo do Produtores do } \\
\text { Queijo Canastra - APROCAN }\end{array}$ & $\mathrm{BR} / \mathrm{MG}$ & Queijo canastra & $\begin{array}{l}\text { Registro concedido } \\
\text { (395) }\end{array}$ & $\begin{array}{c}2149, \mathrm{de} \\
13 / 03 / 2012\end{array}$ \\
\hline 44 & IG201003 & Goiabeiras & IP & $19 / 05 / 2010$ & $\begin{array}{l}\text { Associação das Paneleiras de } \\
\text { Goiabeiras - APG }\end{array}$ & BR/ES & Panelas de barro & $\begin{array}{l}\text { Registro concedido } \\
\text { (395) }\end{array}$ & $\begin{array}{l}2126, \mathrm{de} \\
04 / 10 / 2011\end{array}$ \\
\hline 45 & IG201004 & $\begin{array}{l}\text { Regiäo Pedra Carijó Rio } \\
\text { de Janeiro }\end{array}$ & $\overline{\mathrm{DO}}$ & $23 / 06 / 2010$ & \begin{tabular}{|l|} 
Sindicato de Extração e \\
Aparelhamento de Gnaisses no \\
Noroeste do Estado do Rio de \\
Janeiro - SINDGNAISSES
\end{tabular} & BR/RJ & \begin{tabular}{|l|} 
Gnaisse fitado milonitico de \\
coloraçăo branca e pontos vermelhos \\
de diâmetro geral inferior a 1 \\
centimetro
\end{tabular} & $\begin{array}{l}\text { Registro concedido } \\
\qquad(395)\end{array}$ & $\begin{array}{c}2159, \text { de } \\
22 / 05 / 2012\end{array}$ \\
\hline 46 & IG201005 & \begin{tabular}{|l} 
Regiäo Pedra Madeira \\
Rio de Janeiro
\end{tabular} & $\overline{\mathrm{DO}}$ & $23 / 06 / 2010$ & \begin{tabular}{|l|} 
Sindicato de Extração e \\
Aparelhamento de Gnaisses no \\
Noroeste do Estado do Rio de \\
Janeiro - SINDGNAISSES
\end{tabular} & BR/RJ & $\begin{array}{|lccr|}\text { Gnaisse } & \text { fitado } & \text { milonítico } & \text { de } \\
\text { coloração } & \text { clara } & \text { com } & \text { quatro } \\
\text { variedades de cor: } & \text { branca, } & \text { rosa, } \\
\text { verde e amarela } & & & \\
\end{array}$ & $\begin{array}{l}\text { Registro concedido } \\
\text { (395) }\end{array}$ & $\begin{array}{c}2159, \text { de } \\
22 / 05 / 2012\end{array}$ \\
\hline 47 & IG201006 & \begin{tabular}{|l|} 
Regiäo Pedra Cinza Rio \\
de Janeiro
\end{tabular} & $\overline{D O}$ & $23 / 06 / 2010$ & \begin{tabular}{|l|} 
Sindicato de Extração e \\
Aparelhamento de Gnaisses no \\
Noroeste do Estado do Rio de \\
Janeiro - SINDGNAISSES \\
\end{tabular} & BR/RJ & $\begin{array}{l}\text { Gnaisse fitado milonitico de } \\
\text { coloração cinza possuindo } 3 \\
\text { variedades: "Olho de pombo", "Pinta } \\
\text { Rosa" e "Granito Fino" }\end{array}$ & $\begin{array}{l}\text { Registro concedido } \\
\text { (395) }\end{array}$ & $\begin{array}{c}2159, \text { de } \\
22 / 05 / 2012\end{array}$ \\
\hline 48 & IG201007 & Cachoeiro de Itapemirim & $\overline{I P}$ & $14 / 07 / 2010$ & $\begin{array}{l}\text { Centro Tecnológico de Mármore } \\
\text { e Granito - CETEMAG }\end{array}$ & BR/ES & Mármore & $\begin{array}{l}\text { Registro concedido } \\
\text { (395) }\end{array}$ & $\begin{array}{c}2160, \text { de } \\
29 / 05 / 2012\end{array}$ \\
\hline 49 & IG201008 & Vale dos Vinhedos & $\overline{\mathrm{DO}}$ & $16 / 08 / 2010$ & $\begin{array}{l}\text { Ass. Produtores de Vinhos } \\
\text { Finos do Vale dos Vinhedos - } \\
\text { APOVALE }\end{array}$ & BR/RS & Vinho e espumantes & $\begin{array}{l}\text { Registro concedido } \\
\qquad(395)\end{array}$ & $\begin{array}{c}2177, \text { de } \\
25 / 09 / 2012\end{array}$ \\
\hline
\end{tabular}

\begin{tabular}{|c|c|c|c|c|c|c|c|c|c|}
\hline 50 & IG201009 & Vales da Uva Goethe & IP & $18 / 08 / 2010$ & $\begin{array}{l}\text { Ass. dos Produtores da Uva e } \\
\text { do Vinho Goethe }\end{array}$ & $\mathrm{BR} / \mathrm{SC}$ & $\begin{array}{l}\text { Vinho Branco Seco, Vinho branco } \\
\text { Suave ou Demi Séc, Vinho Leve } \\
\text { Branco Seco, Vinho Leve Branco } \\
\text { Suave ou Demi Séc, Vinho } \\
\text { Espumante Brut, ou Demi Séc } \\
\text { obtidos pelo método "Champenoise", } \\
\text { Vinho Espumante Brut, ou Demi Séc } \\
\text { obtidos pelo método 'Chamat", Vinho } \\
\text { Licoroso }\end{array}$ & $\begin{array}{l}\text { Registro concedido } \\
\text { (395) }\end{array}$ & $\begin{array}{l}2145, \text { de } \\
14 / 02 / 2012\end{array}$ \\
\hline 51 & IG201010 & Säo Joäo del-Rei & IP & $15 / 09 / 2010$ & \begin{tabular}{|l|} 
Associação dos Artesãos de \\
Peças em Estanho de São João \\
del-Rei
\end{tabular} & $\mathrm{BR} / \mathrm{MG}$ & Peças artesanais em Estanho & $\begin{array}{l}\text { Registro concedido } \\
\text { (395) }\end{array}$ & $\begin{array}{c}2144, \text { de } \\
07 / 02 / 2012\end{array}$ \\
\hline \multirow{2}{*}{52} & \multirow[t]{2}{*}{ IG201011 } & \multirow[t]{2}{*}{$\begin{array}{l}\text { Regiäo do Cerrado } \\
\text { Mineiro }\end{array}$} & \multirow[t]{2}{*}{$\overline{D O}$} & \multirow[t]{2}{*}{ 19/11/2010 } & \multirow[t]{2}{*}{$\begin{array}{l}\text { Federação dos Cafeicultores do } \\
\text { Cerrado }\end{array}$} & \multirow[t]{2}{*}{ BR/MG } & \multirow[t]{2}{*}{$\begin{array}{l}\text { Café verde em grão e industrializado } \\
\text { torrado em grão ou moido }\end{array}$} & $\begin{array}{c}\text { Registro concedido } \\
(395)\end{array}$ & $\begin{array}{c}2243, \text { de } \\
31 / 12 / 2013\end{array}$ \\
\hline & & & & & & & & $\begin{array}{c}\text { Petição não } \\
\text { conhecida (410) }\end{array}$ & $\begin{array}{l}2328, \mathrm{de} \\
18 / 08 / 2015\end{array}$ \\
\hline 53 & IG201012 & Franca & IP & $25 / 11 / 2010$ & $\begin{array}{l}\text { Sindicato das Industrias de } \\
\text { Calçados de Franca }\end{array}$ & $\mathrm{BR} / \mathrm{SP}$ & Calçados & $\begin{array}{l}\text { Registro concedido } \\
\text { (395) }\end{array}$ & $\begin{array}{c}\text { 2144, de } \\
07 / 02 / 2012\end{array}$ \\
\hline 54 & IG201013 & Porto & DO & $29 / 11 / 2010$ & $\begin{array}{l}\text { Instituto do Vinho do Douro e } \\
\text { Porto }\end{array}$ & PT & Vinho generoso (vinho licoroso) & $\begin{array}{c}\text { Registro concedido } \\
\text { (395) }\end{array}$ & $\begin{array}{l}2154, \text { de } \\
17 / 04 / 2012\end{array}$ \\
\hline 55 & IG201014 & Pedro II & IP & $17 / 12 / 2010$ & \begin{tabular}{|l|} 
Conselho da União das Ass. E \\
Coop. De garimpeiros, \\
produtores, lapidários e \\
joalheiros de gemas de opalas e \\
de joisas artesanais de opalas \\
\end{tabular} & $\mathrm{BR} / \mathrm{PI}$ & $\begin{array}{l}\text { Opala preciosa de Pedro II e Joias } \\
\text { artesanais de opalas de Pedro II }\end{array}$ & $\begin{array}{l}\text { Registro concedido } \\
\text { (395) }\end{array}$ & $\begin{array}{c}2152, \text { de } \\
03 / 04 / 2012\end{array}$ \\
\hline 56 & IG201101 & Manguezais de Alagoas & DO & $29 / 03 / 2011$ & 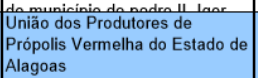 & BR/AL & $\begin{array}{l}\text { Própolis Vermelha e extrato de } \\
\text { própolis vermelha }\end{array}$ & $\begin{array}{l}\text { Registro concedido } \\
\text { (395) }\end{array}$ & $\begin{array}{l}2167, \text { de } \\
17 / 07 / 2012\end{array}$ \\
\hline 57 & IG201102 & Champagne & DO & $04 / 08 / 2011$ & \begin{tabular}{|l|} 
Comté Interprofessionnel Du \\
Vin de Champagne
\end{tabular} & FR & Vinhos Espumantes & $\begin{array}{l}\text { Registro concedido } \\
\text { (395) }\end{array}$ & $\begin{array}{l}\text { 2188, de } \\
11 / 12 / 2012\end{array}$ \\
\hline 58 & IG201103 & Porto Digital & $\mathrm{IP}$ & $05 / 08 / 2011$ & $\begin{array}{l}\text { Núcleo de Gestão do Porto } \\
\text { Digital }\end{array}$ & $\mathrm{BR} / \mathrm{PE}$ & $\begin{array}{l}\text { Serviço de tecnologia de informação } \\
\text { e comunicação através de } \\
\text { desenvolvimento, manutenção e } \\
\text { suporte }\end{array}$ & $\begin{array}{l}\text { Registro concedido } \\
\text { (395) }\end{array}$ & $\begin{array}{c}2188, \mathrm{de} \\
11 / 12 / 2012\end{array}$ \\
\hline 59 & IG201104 & Säo Tiago & $\mathrm{IP}$ & $23 / 08 / 2011$ & $\begin{array}{l}\text { Associação São-Tiaguense dos } \\
\text { produtores de biscoito }\end{array}$ & $\mathrm{BR} / \mathrm{MG}$ & Biscoito & $\begin{array}{l}\text { Registro concedido } \\
\text { (395) }\end{array}$ & $\begin{array}{c}\text { 2196, de } \\
05 / 02 / 2013\end{array}$ \\
\hline 60 & IG201105 & Parmiggiano Reggiano & DO & 19/04/2011 & $\begin{array}{l}\text { Consorzio Del Formaggio } \\
\text { Parmigiano-Reggiano }\end{array}$ & IT & Queijos & Exigência (305) & $\begin{array}{c}\text { 2138, de } \\
27 / 12 / 2011\end{array}$ \\
\hline 61 & IG201106 & Napa Valley & DO & $01 / 09 / 2011$ & Napa Valley Vitners Association & US & Vinho & $\begin{array}{l}\text { Registro concedido } \\
\text { (395) }\end{array}$ & $\begin{array}{l}\text { 2175, de } \\
11 / 09 / 2012\end{array}$ \\
\hline 62 & IG201107 & Divina Pastora & IP & $22 / 09 / 2011$ & $\begin{array}{l}\text { Associação para o Desenv. da } \\
\text { Renda Irlandesa de Divina } \\
\text { Pastora }\end{array}$ & BR/SE & Renda de Agulha em Lacê & $\begin{array}{l}\text { Registro concedido } \\
\text { (395) }\end{array}$ & $\begin{array}{l}2190, \text { de } \\
26 / 12 / 2012\end{array}$ \\
\hline 63 & IG201108 & Mossoró & IP & $28 / 11 / 2011$ & $\begin{array}{l}\text { Comitê Executivo de fruticultura } \\
\text { do RN }\end{array}$ & $\mathrm{BR} / \mathrm{RN}$ & Melão & $\begin{array}{c}\text { Registro concedido } \\
(395)\end{array}$ & $\begin{array}{c}2228, \mathrm{de} \\
17 / 09 / 2013\end{array}$ \\
\hline 64 & \begin{tabular}{|c|} 
BR402012000001-2 \\
(nova numeração)
\end{tabular} & Microrregião Abaira & IP & $09 / 01 / 2012$ & $\begin{array}{l}\text { Ass. dos Prod. de Aguardente } \\
\text { de Qualidade da Micro Regiäo } \\
\text { Abaira }\end{array}$ & $\mathrm{BR} / \mathrm{BA}$ & Aguardente de cana tipo cachaça & $\begin{array}{l}\text { Registro concedido } \\
\text { (395) }\end{array}$ & $\begin{array}{l}2284, \text { de } \\
14 / 10 / 2014\end{array}$ \\
\hline
\end{tabular}




\begin{tabular}{|c|c|c|c|c|c|c|c|c|c|}
\hline 65 & BR402012000002-0 & Altos Montes & IP & $13 / 03 / 2012$ & $\begin{array}{l}\text { Associação de Produtores dos } \\
\text { Vinhos dos Altos Montes }\end{array}$ & BR/RS & Vinhos e espumantes & $\begin{array}{l}\text { Registro concedido } \\
\text { (395) }\end{array}$ & $\begin{array}{l}2188 \text {, de } \\
11 / 12 / 2012\end{array}$ \\
\hline 66 & \begin{tabular}{|l|} 
BR402012000003-9 \\
\end{tabular} & Rio Negro & IP & $24 / 04 / 2012$ & $\begin{array}{l}\text { Cooperativa das pescadoras e } \\
\text { pescadores de Peixes } \\
\text { Ornamentais do Médio e Alto } \\
\text { Rio Negro - ORNAPESCA }\end{array}$ & BR/AM & Peixes ornamentais & $\begin{array}{l}\text { Registro concedido } \\
\text { (395) }\end{array}$ & $\begin{array}{l}2279 \text {, de } \\
09 / 09 / 2014\end{array}$ \\
\hline 67 & BR402012000004-7 & Piauí & IP & $13 / 04 / 2012$ & $\begin{array}{l}\text { Uniäo das Ass. Coop. e } \\
\text { Produtores de cajuina do Piaui - } \\
\text { PROCAJUINA }\end{array}$ & BR/PI & Cajuina & $\begin{array}{c}\text { Registro concedido } \\
\text { (395) }\end{array}$ & $\begin{array}{c}2277, \text { de } \\
26 / 08 / 2014\end{array}$ \\
\hline 68 & BR402012000005-5 & Cariri Paraibano & IP & $13 / 04 / 2012$ & $\begin{array}{l}\text { Conselho Ass. Coop. Emp. Ent. } \\
\text { Renda Renascença-Conarenda }\end{array}$ & BR/PB & Renda Renascença & $\begin{array}{c}\text { Registro concedido } \\
\text { (395) }\end{array}$ & $\begin{array}{c}2229 \text {, de } \\
24 / 09 / 2013\end{array}$ \\
\hline 69 & BR402012000006-3 & Monte Belo & IP & $22 / 08 / 2012$ & $\begin{array}{l}\text { Associaçäo dos vitivinicultores } \\
\text { de Monte Belo do Sul }\end{array}$ & BR/RS & Vinhos e espumantes & $\begin{array}{l}\text { Registro concedido } \\
\text { (395) }\end{array}$ & $\begin{array}{l}2230, \text { de } \\
01 / 10 / 2013\end{array}$ \\
\hline 70 & BR412012000007-8 & Scotch Whisky & DO & $30 / 08 / 2012$ & The Scotch Whisky Association & GB & Uisque & Depositado & \\
\hline 71 & BR412012000009-4 & Rioja & DO & $16 / 11 / 2012$ & $\begin{array}{l}\text { Cons. Regulador da la D.O. } \\
\text { Calificada Rioja }\end{array}$ & ES & Vinho & Exigência (305) & $\begin{array}{r}2224, \text { de } \\
20 / 08 / 2013 \\
\end{array}$ \\
\hline 72 & BR402012000010-1 & Mogiana de Pinhal & $\mathbb{I P}$ & $27 / 12 / 2012$ & $\begin{array}{l}\text { Conselho do Café da Mogiana } \\
\text { de Pinhal - COCAMPI }\end{array}$ & $\mathrm{BR} / \mathrm{SP}$ & Café & Arquivado (325) & $\begin{array}{l}2248, \mathrm{de} \\
04 / 02 / 2014 \\
\end{array}$ \\
\hline 73 & BR412012000011-6 & $\begin{array}{l}\text { Vale Minério de Ferro } \\
\text { S11D }\end{array}$ & DO & $28 / 12 / 2012$ & Vale S. A & BR/MG & Minério de Ferro & Arquivado (325) & $\begin{array}{c}2472, \mathrm{de} \\
22 / 05 / 2018 \\
\end{array}$ \\
\hline 74 & BR412013000001-1 & Prosecco & DO & $17 / 01 / 2013$ & \begin{tabular}{|l} 
Consorzio Di Tutela Della \\
Denominazione Di Origine
\end{tabular} & IT & Vinho & Depositado & \\
\hline 75 & BR412013000002-0 & Ortigueira & DO & $08 / 05 / 2013$ & $\begin{array}{l}\text { Assoc. dos Prod. Ortigueirenses } \\
\text { de Mel - APOMEL }\end{array}$ & BR/PR & Mel de abelha - Apis Mellifera & $\begin{array}{l}\text { Registro concedido } \\
\text { (395) }\end{array}$ & $\begin{array}{c}2330, \mathrm{de} \\
01 / 09 / 2015\end{array}$ \\
\hline 76 & BR402013000003-1 & Regiäo Seridó & $\mathbb{I P}$ & $04 / 06 / 2013$ & $\begin{array}{l}\text { Comitê Regional das Ass. e } \\
\text { Coop. Artesanais do Seridó - } \\
\text { CRACAS }\end{array}$ & BR/RN & Bordados do Seridó & Arquivado (325) & $\begin{array}{c}2248 \text {, de } \\
04 / 02 / 2014\end{array}$ \\
\hline 77 & BR402013000004-0 & Pantanal & IP & $22 / 08 / 2013$ & $\begin{array}{l}\text { Conselho das Cooperativas, } \\
\text { Associaçôes, Entrepostos e } \\
\text { Empresas de Afins a Apicultura } \\
\text { do Pantanal do Brasil - } \\
\text { CONFENAL }\end{array}$ & BR/MS & Mel & $\begin{array}{c}\text { Registro concedido } \\
\text { (395) }\end{array}$ & $\begin{array}{c}2305, \mathrm{de} \\
10 / 03 / 2015\end{array}$ \\
\hline 78 & BR412013000005-4 & \begin{tabular}{|l} 
Regiäo da Própolis \\
Verde de Minas Gerais
\end{tabular} & DO & $30 / 09 / 2013$ & $\begin{array}{l}\text { FEMAP - Federação Mineira de } \\
\text { Apicultura }\end{array}$ & BR/MG & Própolis Verde & $\begin{array}{l}\text { Registro concedido } \\
\text { (395) }\end{array}$ & $\begin{array}{c}2383, \mathrm{de} \\
06 / 09 / 2016\end{array}$ \\
\hline 79 & BR402013000006-6 & Regiäo de Mara Rosa & $\mathbb{I P}$ & $11 / 10 / 2013$ & $\begin{array}{l}\text { Cooperativa dos Produtores de } \\
\text { Açafrão de Mara Rosa - } \\
\text { COOPERAÇAFRÃO }\end{array}$ & $\mathrm{BR} / \mathrm{GO}$ & Açafrão & $\begin{array}{c}\text { Registro concedido } \\
(395)\end{array}$ & $\begin{array}{c}2352, \mathrm{de} \\
02 / 02 / 2016\end{array}$ \\
\hline 80 & BR402014000001-8 & Regiäo de Pinhal & $\mathbb{I P}$ & $05 / 02 / 2014$ & $\begin{array}{l}\text { Conselho do Café da Mogiana } \\
\text { de Pinhal - COCAMPI }\end{array}$ & BR/SP & Café Verde e Café Torrado e Moido & $\begin{array}{l}\text { Registro concedido } \\
\text { (395) }\end{array}$ & $\begin{array}{c}2376 \text {, de } \\
19 / 07 / 2016\end{array}$ \\
\hline 81 & BR402014000002-6 & $\begin{array}{l}\text { Venda Nova do } \\
\text { Imigrante }\end{array}$ & $\mathbb{I P}$ & $03 / 07 / 2014$ & $\begin{array}{l}\text { Associaçäo dos Produtores de } \\
\text { Socol de Venda Nova do } \\
\text { Imigrante - ASSOCOL }\end{array}$ & BR/ES & Socol & $\begin{array}{l}\text { Registro concedido } \\
\text { (395) }\end{array}$ & $\begin{array}{c}2475, \text { de } \\
12 / 06 / 2018\end{array}$ \\
\hline
\end{tabular}

\begin{tabular}{|c|c|c|c|c|c|c|c|c|c|}
\hline 82 & BR402014000003-4 & Extremo Norte Capixaba & $\mathbb{I P}$ & \begin{tabular}{l|l}
$03 / 07 / 2014$ \\
\end{tabular} & $\begin{array}{l}\text { Associação dos Produtores de } \\
\text { Carne de Sol do Extremo Norte } \\
\text { Capixaba }\end{array}$ & BR/ES & Carne de sol & Arquivado (325) & $\begin{array}{c}2466 \text {, de } \\
10 / 04 / 2018\end{array}$ \\
\hline 83 & BR402014000004-2 & \begin{tabular}{|l} 
Regiäo Säo Bento de \\
Urânia
\end{tabular} & $\mathbb{I P}$ & $03 / 07 / 2014$ & $\begin{array}{l}\text { Associação dos Produtores de } \\
\text { Inhame S. Bento do Espirito } \\
\text { Santo - apisbes }\end{array}$ & BR/ES & Inhame & $\begin{array}{l}\text { Registro concedido } \\
\text { (395) }\end{array}$ & $\begin{array}{c}2385, \text { de } \\
20 / 09 / 2016\end{array}$ \\
\hline 84 & BR402014000005-0 & Oeste da Bahia & $\mathbb{I P}$ & $17 / 07 / 2014$ & $\begin{array}{l}\text { Associação dos Cafeicultores do } \\
\text { Oeste da Bahia - ABACAFE }\end{array}$ & $\overline{B R / B A}$ & $\begin{array}{l}\text { Café verde em grãos, da espécie } \\
\text { Coffea arabica }\end{array}$ & Exigência (305) & $\begin{array}{l}2487 \text {, de } \\
04 / 09 / 2018\end{array}$ \\
\hline 85 & BR402014000006-9 & Farroupilha & $\mathbb{I P}$ & $25 / 07 / 2014$ & \begin{tabular}{|l|} 
Associação Farroupilhense de \\
Produtores de Vinhos, \\
Espumantes, sucos e derivados \\
- Afavin
\end{tabular} & BR/RS & $\begin{array}{l}\text { Vinho Fino Branco Moscatel, Vinho } \\
\text { Moscatel Espumante; Vinho Frisante } \\
\text { Moscatel; Vinho Licoroso Moscatel; } \\
\text { Mistela Simples Moscatel; Brandy de } \\
\text { Vinho Moscatel }\end{array}$ & $\begin{array}{l}\text { Registro concedido } \\
\text { (395) }\end{array}$ & $\begin{array}{l}2323, \text { de } \\
14 / 07 / 2015\end{array}$ \\
\hline 86 & BR402014000007-7 & Maracaju & $\mathbb{I P}$ & $30 / 07 / 2014$ & $\begin{array}{l}\text { Associação dos Produtores da } \\
\text { Tradicional Linguiça de } \\
\text { Maracaju - APTRALMAR }\end{array}$ & BR/MS & Linguiça & $\begin{array}{l}\text { Registro concedido } \\
\text { (395) }\end{array}$ & $\begin{array}{c}2342 \text {, de } \\
24 / 11 / 2015\end{array}$ \\
\hline 87 & BR412014000008-1 & Aveiro & DO & $12 / 09 / 2014$ & $\begin{array}{l}\text { APOMA - Associação de } \\
\text { Produtores de Ovos Moles de } \\
\text { Aveiro }\end{array}$ & PT & $\begin{array}{l}\text { Doce tradicional português chamado } \\
\text { Ovos Moles de Aveiro }\end{array}$ & Depositado & \\
\hline 88 & BR402014000009-3 & Sabará & $\mathbb{I P}$ & $23 / 09 / 2014$ & $\begin{array}{l}\text { Associação dos Produtores de } \\
\text { Derivados de Jabuticaba de } \\
\text { Sabará }\end{array}$ & BR/MG & $\begin{array}{l}\text { 1-Licor de Jabuticaba; 2-Geleia de } \\
\text { Jabuticaba; 3-Molho de Jabuticaba; } 4 \text { - } \\
\text { Casca de Jabuticaba Cristalizada; } 5 \text { - } \\
\text { Compota de Jabuticaba }\end{array}$ & $\begin{array}{l}\text { Pedido publicado } \\
\text { (335) }\end{array}$ & $\begin{array}{l}2438 \text {, de } \\
26 / 09 / 2017\end{array}$ \\
\hline 89 & BR402014000010-7 & Tomé-Açu & IP & $28 / 10 / 2014$ & $\begin{array}{l}\text { Associação Cultural e Fomento } \\
\text { Agricola de Tomé-Açu - ACTA }\end{array}$ & $\mathrm{BR} / \mathrm{PA}$ & Cacau & Exigência (305) & $\begin{array}{c}2480, \text { de } \\
17 / 07 / 2018\end{array}$ \\
\hline 90 & BR402014000011-5 & Sul da Bahia & IP & $24 / 11 / 2014$ & $\begin{array}{l}\text { Associação dos Produtores de } \\
\text { Cacau do Sul da Bahia }\end{array}$ & BR/BA & $\begin{array}{l}\text { Amêndoas de cacau (Theobroma } \\
\text { Cacao L.) }\end{array}$ & $\begin{array}{l}\text { Registro concedido } \\
\text { (395) }\end{array}$ & $\begin{array}{c}2468 \text {, de } \\
24 / 04 / 2018\end{array}$ \\
\hline 91 & BR402014000012-3 & \begin{tabular}{|l} 
Regiäo das Lagoas \\
Mundaú-Manguaba
\end{tabular} & $\mathbb{I P}$ & $09 / 12 / 2014$ & $\begin{array}{l}\text { Instituto Bordado Filé das } \\
\text { lagoas Mundaú Manguaba }\end{array}$ & BR/AL & Bordado Filé & $\begin{array}{l}\text { Registro concedido } \\
\text { (395) }\end{array}$ & $\begin{array}{c}2363, \text { de } \\
19 / 04 / 2016\end{array}$ \\
\hline 92 & BR402015000001-0 & Maués & IP & $06 / 02 / 2015$ & $\begin{array}{l}\text { Associação dos Produtores de } \\
\text { Guaraná da Indicação } \\
\text { Geográfica de Maués }\end{array}$ & BR/AM & $\begin{array}{l}\text { Guaraná da espécie Paullinia cupana } \\
\text { Var. Sorbilis }\end{array}$ & $\begin{array}{l}\text { Registro concedido } \\
\text { (395) }\end{array}$ & $\begin{array}{c}2454, \text { de } \\
16 / 01 / 2018\end{array}$ \\
\hline 93 & BR402015000002-9 & Cruzeiro do Sul & $\mathbb{I P}$ & $16 / 10 / 2015$ & $\begin{array}{l}\text { Central das Coop. dos Prod. } \\
\text { Familiares do Vale do Juruá - } \\
\text { CENTRAL JURUÁ }\end{array}$ & $\mathrm{BR} / \mathrm{AC}$ & Farinha de Mandioca & $\begin{array}{l}\text { Registro concedido } \\
\text { (395) }\end{array}$ & $\begin{array}{c}2433, \text { de } \\
22 / 08 / 2017\end{array}$ \\
\hline 94 & BR402015000003-7 & Marialva & $\mathbb{I P}$ & $21 / 10 / 2015$ & $\begin{array}{l}\text { Associação Norte Noroeste } \\
\text { Paranaense dos Fruticultores } \\
\text { (ANFRUT) }\end{array}$ & BR/PR & Uvas Finas de Mesa & $\begin{array}{l}\text { Registro concedido } \\
\text { (395) }\end{array}$ & $\begin{array}{c}2425, \text { de } \\
27 / 06 / 2017\end{array}$ \\
\hline 95 & BR402015000004-5 & Antonina & $\mathbb{I P}$ & $27 / 10 / 2015$ & $\begin{array}{l}\text { Agência de Desenvolvimento do } \\
\text { Turismo Sustentável do Litoral } \\
\text { do Paraná }\end{array}$ & $\mathrm{BR} / \mathrm{PR}$ & Bala de banana & Exigência (305) & $\begin{array}{l}2413, \text { de } \\
04 / 04 / 2017\end{array}$ \\
\hline 96 & BR402015000005-3 & Litoral do Paraná & IP & $27 / 10 / 2015$ & \begin{tabular}{|l|} 
Agência de Desenvolvimento do \\
Turismo Sustentável do Litoral \\
do Paraná
\end{tabular} & BR/PR & Serviço Gastronômico do Barreado & Depositado & \\
\hline
\end{tabular}




\begin{tabular}{|c|c|c|c|c|c|c|c|c|c|}
\hline 97 & BR402015000006-1 & Morretes & IP & 27/10/2015 & \begin{tabular}{|l|} 
Agência de Desenvolvimento do \\
Turismo Sustentável do Litoral \\
do Paraná
\end{tabular} & $\begin{array}{l}\text { BR/PR } \\
\end{array}$ & Cachaça e Aguardente de Cana & Depositado & \\
\hline 98 & BR402015000007-0 & Litoral do Paraná & IP & $27 / 10 / 2015$ & $\begin{array}{l}\text { Agência de Desenvolvimento do } \\
\text { Turismo Sustentável do Litoral } \\
\text { do Paraná }\end{array}$ & BR/PR & Farinha de Mandioca & Depositado & \\
\hline 99 & BR402015000008-8 & Carlópolis & IP & 28/10/2015 & $\begin{array}{l}\text { Associação dos Olericultores e } \\
\text { Fruticultores de Carlópolis } \\
\text { (APC) }\end{array}$ & $\mathrm{BR} / \mathrm{GO}$ & Goiaba & $\begin{array}{l}\text { Registro concedido } \\
\text { (395) }\end{array}$ & $\begin{array}{l}\text { 2367, de } \\
17 / 05 / 2016\end{array}$ \\
\hline 100 & BR402015000009-6 & Capanema & IP & $29 / 10 / 2015$ & $\begin{array}{l}\text { Associação de Turismo de Doce } \\
\text { Iguassu }\end{array}$ & BR/PR & Melado & Exigência (305) & $\begin{array}{c}2489 \text {, de } \\
18 / 09 / 2018\end{array}$ \\
\hline 101 & BR402015000010-0 & Colônia Witmarsum & IP & $04 / 11 / 2015$ & $\begin{array}{l}\text { Cooperativa Mista Agropecuária } \\
\text { Witmarsum Lida }\end{array}$ & BR/PR & Queijo & $\begin{array}{l}\text { Registro concedido } \\
\text { (395) }\end{array}$ & $\begin{array}{c}2468 \text {, de } \\
24 / 04 / 2018\end{array}$ \\
\hline 102 & BR402015000011-8 & São Matheus & IP & $04 / 11 / 2015$ & $\begin{array}{l}\text { Associaçāo dos Amigos da Erva } \\
\text { Mate de São Mateus }\end{array}$ & BR/PR & Erva-mate & $\begin{array}{l}\text { Registro concedido } \\
\text { (395) }\end{array}$ & $\begin{array}{c}2425 \text {, de } \\
27 / 06 / 2017\end{array}$ \\
\hline 103 & BR402015000012-6 & Oeste do Paraná & IP & $09 / 12 / 2015$ & $\begin{array}{l}\text { Cooperativa Agro familiar } \\
\text { Solidária - COOFAMEL }\end{array}$ & BR/PR & $\begin{array}{l}\text { Mel de Abelha Apis Melifera } \\
\text { Escutelata (Apis Africanizada) - Mel } \\
\text { de Abelha Tetragonisca Angustula } \\
\text { (Jatai) }\end{array}$ & $\begin{array}{l}\text { Registro concedido } \\
\text { (395) }\end{array}$ & $\begin{array}{l}2426 \text {, de } \\
04 / 07 / 2017\end{array}$ \\
\hline 104 & BR412016000001-0 & Mantiqueira de Minas & DO & 05/05/2016 & $\begin{array}{l}\text { Associação dos Produtores de } \\
\text { Café da Mantiqueira }\end{array}$ & BR/MG & $\begin{array}{l}\text { Café verde em grãos e café } \\
\text { industrializado torrado e/ou moido }\end{array}$ & Exigência (305) & $\begin{array}{c}2482 \text {, de } \\
31 / 07 / 2018\end{array}$ \\
\hline 105 & BR402016000002-1 & $\begin{array}{l}\text { Petrolina-PE, Juazeiro- } \\
\text { BA }\end{array}$ & $\mathbb{I P}$ & $09 / 08 / 2016$ & $\begin{array}{l}\text { Amilton Soares Guimarães } \\
\text { Petrolina }\end{array}$ & BR/PE & $\begin{array}{l}\text { Panificadora e lanchonete, produtos } \\
\text { para padaria, confeitaria e pastelaria, } \\
\text { exceto industriais }\end{array}$ & Arquivado (325) & $\begin{array}{c}2454, \text { de } \\
16 / 01 / 2018\end{array}$ \\
\hline 106 & BR412016000003-6 & $\begin{array}{l}\text { Banana da Regiäo de } \\
\text { Corupá }\end{array}$ & DO & $01 / 09 / 2016$ & $\begin{array}{l}\text { Associação dos Bananicultores } \\
\text { da Regiāo de Corupá }\end{array}$ & BR/SC & Banana (subgrupo Cavendish) & $\begin{array}{c}\text { Registro concedido } \\
\text { (395) }\end{array}$ & $\begin{array}{c}2486 \text {, de } \\
28 / 08 / 2018\end{array}$ \\
\hline 107 & BR402016000004-4 & Gorgonzola & DO & $01 / 11 / 2016$ & Conzorzio per la Tutela del Form & IT & Queijo & Depositado & \\
\hline 108 & BR412016000005-2 & $\begin{array}{l}\text { Terra Indigena Andirá- } \\
\text { Marau }\end{array}$ & $\overline{\mathrm{DO}}$ & $20 / 10 / 2016$ & $\begin{array}{l}\text { Consórcio dos Produtores } \\
\text { Sateré-Mawé-CPSM }\end{array}$ & $\overline{\text { BRIAM }}$ & $\begin{array}{l}\begin{array}{l}\text { Guaraná em pó, pães de guaraná } \\
\text { (bastão), } \\
\text { casquilho de guaraná }\end{array} \\
\end{array}$ & Exigência (305) & $\begin{array}{c}2490, \text { de } \\
25 / 09 / 2018\end{array}$ \\
\hline 109 & BR412017000001-2 & Brasil Bahia & DO & $21 / 02 / 2017$ & $\begin{array}{l}\text { Sindicato da Indústria do } \\
\text { Tabaco no Estado da Bahia }\end{array}$ & BR/BA & Charuto & Exigência (305) & $\begin{array}{c}2488 \text {, de } \\
11 / 09 / 2018\end{array}$ \\
\hline 110 & BR402017000002-4 & Emilia & IP & 08/03/2017 & Consorzio Tutela Vini Emlilia & IT & Vinhos & Depositado & \\
\hline
\end{tabular}

\begin{tabular}{|c|c|c|c|c|c|c|c|c|}
\hline 111 & BR402017000003-2 & Regiāo de Uarini & $\mathbb{I P}$ & $02 / 05 / 2017$ & \begin{tabular}{|l|} 
Associação dos Produtores de \\
Farinha de Mandioca da Região \\
de Uarini
\end{tabular} & BR/AM & Farinha de Mandioca & Depositado \\
\hline 112 & BR402017000004-0 & \begin{tabular}{|l} 
Regiāo de Novo \\
Remanso
\end{tabular} & $\mathbb{I P}$ & $02 / 05 / 2017$ & $\begin{array}{l}\text { Associação dos Produtores de } \\
\text { Abacaxi da Região de Novo } \\
\text { Remanso-Encarem }\end{array}$ & BR/AM & Abacaxi & Depositado \\
\hline 113 & BR402017000005-9 & \begin{tabular}{|l} 
Algodão de Mato \\
Grosso
\end{tabular} & IP & $29 / 08 / 2017$ & $\begin{array}{l}\text { Associação Matogrossense dos } \\
\text { Produtores de Algodão }\end{array}$ & BR/MT & Algodão & Depositado \\
\hline 114 & BR412017000006-3 & $\begin{array}{l}\text { Campos de Cima da } \\
\text { Serra }\end{array}$ & DO & 11/09/2017 & $\begin{array}{l}\text { Federação das Associaçōes de } \\
\text { Produtores de Queijo Artesanal } \\
\text { Serrano de SC e RS }\end{array}$ & $\mathrm{BR} / \mathrm{SC}$ & Queijo Artesanal Serrano & Depositado \\
\hline 115 & BR412017000007-1 & Campana & $\mathrm{DO}$ & 15/09/2017 & \begin{tabular}{|l|} 
Consorzio per la Tutela del \\
Formaggio Mozzarella di Bufala
\end{tabular} & IT & Muçarela de búfala & Depositado \\
\hline 116 & BR402017000008-3 & Pirenópolis & $\mathbb{I P}$ & $12 / 12 / 2017$ & \begin{tabular}{|l|} 
Associação Cultural e Ecológico \\
dos Artesaõs em prata de \\
Pirenópolis
\end{tabular} & $\mathrm{BR} / \mathrm{GO}$ & Joias Artesanais em Prata & Depositado \\
\hline 117 & BR402017000009-1 & Campanha Gaúcha & $\mathbb{I P}$ & $14 / 12 / 2017$ & $\begin{array}{l}\text { Associação dos Produtores de } \\
\text { Vinhos Finos da Campanha } \\
\text { Gaúcha }\end{array}$ & BR/RS & $\begin{array}{l}\text { Vinho fino branco tranquilo; Vinho } \\
\text { fino rosado tranquilo; Vinho fino tinto } \\
\text { tranquilo; Vinho Espumante fino }\end{array}$ & Depositado \\
\hline 118 & BR402017000010-5 & Vale do Itaúnas & $\mathbb{I P}$ & $21 / 12 / 2017$ & $\begin{array}{l}\text { Associação dos Produtores de } \\
\text { Carne de Sol do Extremo Norte } \\
\text { Capixaba }\end{array}$ & BR/ES & Carne de sol & Depositado \\
\hline 119 & BR402018000001-9 & Caicó & IP & $25 / 06 / 2018$ & \begin{tabular}{|l|} 
Comitê Regional das \\
Associaçōes e Cooperativas \\
Artesanais de Seridó- CRACAS
\end{tabular} & $\mathrm{BR/RN}$ & Bordado & Depositado \\
\hline 120 & BR402018000002-7 & Matas de Minas & IP & $05 / 07 / 2018$ & $\begin{array}{l}\text { Conselho das Entidades do } \\
\text { Café das Matas de Minas }\end{array}$ & BR/MG & $\begin{array}{l}\text { Café em grãos crus, beneficiados, } \\
\text { torrados e torrados e moidos }\end{array}$ & Depositado \\
\hline 121 & BR412018000003-1 & Baia da llha Grande & $\mathrm{DO}$ & $26 / 07 / 2018$ & \begin{tabular}{|l|} 
Associação de Maricultores da \\
Baia da llha Grande - AMBIG
\end{tabular} & BR/RJ & Vieiras (Nodipecten Nodosus) & Depositado \\
\hline 122 & BR402018000004-3 & Gramado & IP & $26 / 07 / 2018$ & $\begin{array}{l}\text { Associação das Indústrias de } \\
\text { Chocolate Caseiro de Gramado }\end{array}$ & BR/RS & Chocolate Artesanal & Depositado \\
\hline
\end{tabular}

